Review Article

\title{
The Beta-Amyloid Protein of Alzheimer's Disease: Communication Breakdown by Modifying the Neuronal Cytoskeleton
}

\author{
Sara H. Mokhtar, ${ }^{1}$ Maha M. Bakhuraysah, ${ }^{1}$ David S. Cram, ${ }^{2}$ and Steven Petratos ${ }^{1,3}$ \\ ${ }^{1}$ Department of Anatomy and Developmental Biology, Monash University, Clayton, VIC 3800, Australia \\ ${ }^{2}$ Monash University, Clayton, VIC 3800, Australia \\ ${ }^{3}$ Department of Medicine, Central Clinical School, Monash University, Prahran, Clayton, VIC 3004, Australia \\ Correspondence should be addressed to Steven Petratos; steven.petratos@monash.edu
}

Received 2 October 2013; Accepted 7 November 2013

Academic Editor: Jesús Avila

Copyright (C) 2013 Sara H. Mokhtar et al. This is an open access article distributed under the Creative Commons Attribution License, which permits unrestricted use, distribution, and reproduction in any medium, provided the original work is properly cited.

Alzheimer's disease $(\mathrm{AD})$ is one of the most prevalent severe neurological disorders afflicting our aged population. Cognitive decline, a major symptom exhibited by $\mathrm{AD}$ patients, is associated with neuritic dystrophy, a degenerative growth state of neurites. The molecular mechanisms governing neuritic dystrophy remain unclear. Mounting evidence indicates that the AD-causative agent, $\beta$-amyloid protein $(\mathrm{A} \beta)$, induces neuritic dystrophy. Indeed, neuritic dystrophy is commonly found decorating $\mathrm{A} \beta$-rich amyloid plaques (APs) in the AD brain. Furthermore, disruption and degeneration of the neuronal microtubule system in neurons forming dystrophic neurites may occur as a consequence of $A \beta$-mediated downstream signaling. This review defines potential molecular pathways, which may be modulated subsequent to $A \beta$-dependent interactions with the neuronal membrane as a consequence of increasing amyloid burden in the brain.

\section{Introduction}

Several neurodegenerative disorders share common characteristics including aggregation of misfolded mutant proteins in neurons leading to their deafferentation or loss with resultant structural or functional deficits in specific regions of the central nervous system (CNS) [1]. The most prevalent symptoms of age-related neurodegenerative disease are cognitive decline and movement disorders, along with brainstem and cerebellar signs. Such age-dependent disorders include Alzheimer's disease (AD), Huntington's disease (HD), Parkinson's disease (PD), and Spinal Cerebellar Ataxias (SCAs) [1]. There exists complexity in identifying fundamental molecular mechanisms precipitating neurodegeneration in these age-related brain diseases. However, common molecular signalling pathways have been defined in the specific neuronal populations associated with pathology [2]. Although the initiators of neuronal dysfunction may differ for each neurodegenerative disorder, there may be common molecular pathways which when being dysregulated, drive and exacerbate neurodegeneration. For example, the degeneration seen in AD is a result of amyloid plaques and phosphorylated tau deposition in the cerebral cortex and specific subcortical regions, leading to degeneration in the temporal lobe and parietal lobe, along with parts of the frontal cortex and cingulate gyrus [2]. AD also displays dysregulation in kinase and phosphatase mechanisms along with microtubule motor proteins during the degeneration phase $[3,4]$. Therefore, a major question that remains unresolved is whether the dysregulation in specific kinases/phosphatases and vesicular transport mechanisms are aetiological contributors to $\mathrm{AD}$ pathology.

\section{Neurodegeneration and Alzheimer's Disease (AD)}

Over the past century, the ageing of our population $(\geq 65$ years) in industrialised countries has exceeded that of the population as a whole. It is predicted that in subsequent 
generations, the proportion of the elderly population will double and so will the proportion of persons suffering from neurodegenerative disorders [5]. Diagnosis of neurodegenerative disease is usually based on clinical symptoms as there are no suitable noninvasive tests that can specifically predict onset of these conditions. However, with the advent of specialised magnetic resonance imaging (MRI) techniques, it is now possible to detect early pathological changes in the brain [6], providing clinicians with a unique window for early therapeutic intervention. Nevertheless, it is imperative that biomarker(s) of neurodegeneration are identified to assist in the early detection of these idiopathic cognitive disorders. Such biomarkers may take the form of modified proteins or peptides that are released into the circulation or alternatively sequestered intrathecally $[1,2]$.

Biomarkers of neurodegeneration may well be derived from dysfunctional/modified proteins that form the basis of pathological signal transduction cascades [1]. The dysregulation of signalling molecules central for maintaining neuronal function may stimulate the onset of neurodegeneration. For example, while Rho kinase (mainly ROCKII), glycogen synthase kinase- $3 \beta$ (GSK- $3 \beta$ ), cyclin-dependent kinase5 (Cdk5), and phosphatases are all essential for normal neuronal development [7], they may all be involved in a plethora of neurodegenerative disorders through a central pathogenic mechanism.

\section{Amyloid Beta $(\mathrm{A} \beta)$ and Amyloid Plaque Pathology}

It is well documented that the aging process is the major determinant of developing amyloid plaques with or without disease [8]. These extracellular senile plaques are composed of accumulated $\mathrm{A} \beta$ protein aggregating as $\beta$-pleated sheets and are derived from the aberrant cleavage of the transmembrane protein, APP [9-11]. Under normal physiological conditions, APP is a cell surface protein that is thought to be involved in signal transduction, axonal elongation, and cell migration [12-20]. It was also demonstrated that the Cterminus of APP plays a central role in gene expression and neuronal cell survival [21]. Such physiological mechanisms are only effective when APP is cleaved by various enzymes which can include intramembranous degradation by beta-site $\mathrm{A} \beta \mathrm{PP}$-cleaving enzyme (BACE1) to form the $\beta \mathrm{C}$-terminal fragment ( $\beta$ CTF) [22, 23], subsequently followed by gammasecretase which forms the small 4 kilodalton $(\mathrm{kDa})$ amyloid$\beta(\mathrm{A} \beta)$ peptides $\mathrm{A} \beta 1-40$ and $\mathrm{A} \beta 1-42$, which are released at the synapse (Figure 1) $[22,24,25]$. It has been demonstrated that the extent of APP cleavage is amplified in AD brains and that $\mathrm{A} \beta$ treatment further enhances this cleavage [21]. It has also been established that APP and its degradation products localise to neuritic vesicles [26] in the axons of $\mathrm{AD}$ brains, along with other neurodegenerative diseases, suggesting that APP accumulation may represent a hallmark of axonal injury $[27,28]$. For instance, in APP transgenic mice, it has been demonstrated that elevated $\mathrm{A} \beta$ levels result in the loss of synapses and neuronal transmission along with behavioural abnormalities, before the formation of amyloid

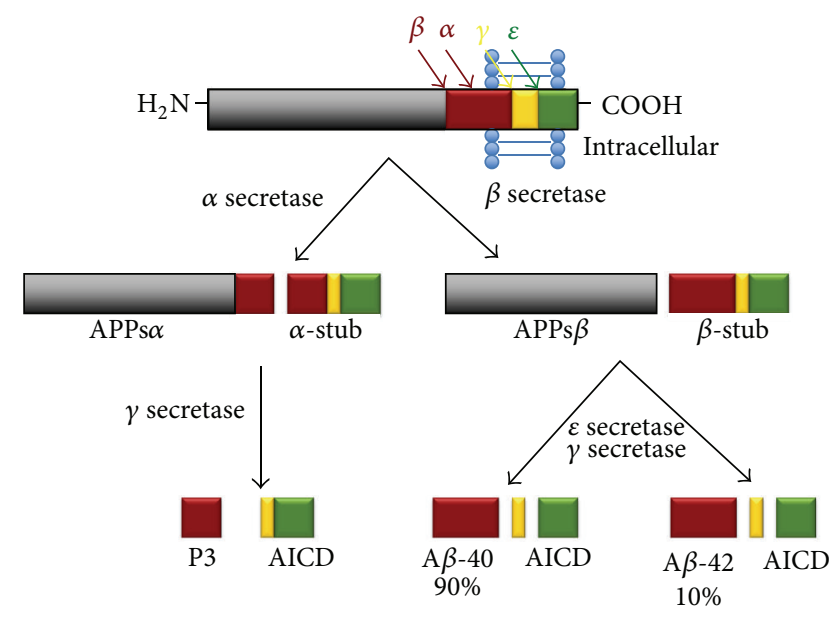

FIgURE 1: The processing of APP through the beta-site A $\beta$ PPcleaving enzyme BACE1, followed by presenilin-1 (PS1). Sequential beta and gamma-secretase cleavage of APP generates the synaptotoxic amyloid- $\beta(\mathrm{A} \beta)$ peptide species, $\mathrm{A} \beta 1-40$ and $\mathrm{A} \beta 1-42$.

plaques [21]. Accumulation of $A \beta$, mainly $A \beta 1-42$, results in the rare early-onset familial AD (EOFAD) which is caused by mutations in the enzymes that cleave APP, leading to rapid and aberrant cleavage with resultant overproduction of $A \beta$ [29]. On the other hand, the common late-onset $\mathrm{AD}$ (LOAD) is thought to result from either the failure of $A \beta$ to be cleared from the brain $[30,31]$ by microglial cells, lower expression of $\mathrm{A} \beta$ degrading proteases such as insulysin (insulin degrading enzyme IDE), a decline in the availability of $\mathrm{A} \beta$ chaperone low density lipoprotein receptor-related protein (LRP1) to transport $A \beta$ out of the brain, reduced vascular and perivascular drainage, or a combination of the above [32]. Although $\mathrm{A} \beta$ monomers are relatively nonpathogenic, accumulating soluble $A \beta$ oligomeric forms have been shown to be synaptotoxic and can prune dendritic spines, disconnecting the memory-encoding neuronal network in the entorhinal cortex, the parahippocampal gyrus, and the hippocampus [33]. These oligomers eventually form large insoluble fibrillar aggregates or plaques that by themselves do not directly induce neuronal death but rather attract microglia and astrocytes that produce cytotoxic proinflammatory cytokines and reactive oxygen species that may indirectly cause neuronal death [34].

Additionally, other proposed mechanisms that contribute to neuronal damage include the vulnerability of cells to secondary insults, tau hyperphosphorylation, induction of the apoptosome and lysosomal protease activity, changes in calcium influx, and direct damage (peroxidation) of membranes [35].

Although the plaques are found extracellularly, it is thought that production, oligomerisation, and accumulation of $\mathrm{A} \beta$ occur within neuronal processes with the possibility that the incorporation of aggregates into plaques occurs after the neurites are dissolved [36]. Certainly, studies performed in the well-established mouse models of AD have identified $\mathrm{A} \beta$ in several neuronal compartments such as the Golgi 
apparatus, the endoplasmic reticulum, the secretory vesicles, endosomes, and autophagic vacuoles, suggesting intraneuronal aggregation and pathology [36]. However, recent evidence supports the extracellular deposition of $\mathrm{A} \beta$ as the initiating pathogenic mechanism in the $\mathrm{AD}$ brain [37], with a direct correlation with the inhibition of anterograde axonal transport [38]. Despite direct evidence of $A \beta$-dependent neurodegeneration, $A \beta$ pathology occurs prior to the appearance of clinical symptoms [37]. Accordingly, determining the level of amyloid deposition in an $\mathrm{AD}$ patient's brain $(\mathrm{A} \beta$ load) in a time-dependent manner would be informative in evaluating the progression of the disease and monitoring patient's response to antiamyloid therapies. Interestingly, through amyloid imaging, recent studies have demonstrated binding of the PET Pittsburgh compound $\mathrm{B}$ (PiB-PET) to $\mathrm{A} \beta$ peptides [39]. In this study, $\mathrm{PET}$ amyloid imaging with Pittsburgh compound $\mathrm{B}(\mathrm{PiB})$ showed increased cortical $\mathrm{PiB}$ binding in $\mathrm{AD}$ patients when compared to control subjects and intermediate binding levels in patients with mild cognitive impairment (MCI) [39]. This compound could be beneficial in the early detection of $\mathrm{AD}$ and evaluation of disease progression.

Recently, it was demonstrated by a combination of in vivo and in vitro studies that $\mathrm{A} \beta$ binding to the cellular prion protein $(\mathrm{PrPc})$, an oligomer-specific high-affinity binding site for $\mathrm{A} \beta$, can play a central role in $\mathrm{A} \beta$-induced memory deficits, axon degeneration, synapse loss, and neuronal death in the $\mathrm{AD}$ brain through Fyn kinase activation [40]. The activation of this kinase results in alterations in N-methyl-Daspartate receptor (NMDAR) function by increasing surface NMDAR expression along with its phosphorylation, and eventually leading to dendritic spine, in association with surface receptor loss [40]. The data suggests that by inhibiting PrPc in the APPswe/PSEN1-M146L double transgenic mouse, reversal of memory deficits and restoration of synaptic density could be achieved [40]. It has been demonstrated that Fyn kinase associates with the tau protein and that abnormal Fyntau interactions sensitise synapses to glutamate excitoxicity [40]. Together, these data suggest that PrPc-Fyn signalling may contribute to $\mathrm{A} \beta$ and tau pathologies and thus its downregulation may be a potential therapeutic approach.

\section{Tau Protein Pathology}

The tau protein is an integral component of the neuronal cytoskeleton [41] with a molecular weight ranging from $45 \mathrm{kDa}$ to $65 \mathrm{kDa}$ [41] and is responsible for the promotion of microtubule assembly in the normal brain [42]. Microtubule assembly is tightly regulated by a combination of protein kinases and phosphatases that balance the amount of tau phosphorylation $[43,44]$. The most common tau pathology is seen in $\mathrm{AD}$, but it is manifest in other diseases such as frontotemporal dementias and Parkinson's disease [45, 46]. In the $\mathrm{AD}$ brain, tau exists in a hyperphosphorylated state, which leads to aberrant secondary structures and loss of function, resulting in a reduced ability to bind to microtubules and to promote their assembly [47]. The abnormal translocation of tau from axonal microtubules to neuropil thread inclusions, cell bodies and dendritic processes, where tau aggregates and accumulates, are pther prominent cytopathological hallmarks observed within AD brain sections [48]. The tau protein is initially synthesised as a single chain polypeptide and then targeted by posttranslational modifications that alter its conformation, promoting tau dimerisation in an antiparallel manner [49]. Stable tau dimers subsequently form tau oligomers, which aggregate at an increasing rate to form subunits of filaments, called protomers. Two protomers twisted around each other with a crossover repeat of $80 \mathrm{~nm}$, constitute the width varying between w10 and w $22 \mathrm{~nm}$ to form paired helical filaments (PHFs), a characteristic of $\mathrm{AD}$ neuronal pathology $[49,50]$. Assembly of PHFs finally establishes the neurofibrillary tangles (NFTs), which can be observed microscopically (Figure 2) [51]. Hyperphosphorylated tau sequesters normal tau and other neuronal microtubule associated proteins (MAPs), such as MAP1A, MAP1B, and MAP2, contributing further to disassembled microtubules, disruption of the axonal cytoskeleton, and transport, culminating as damaged neurons [52]. After neuronal death, tau oligomers are released into the extracellular environment which leads to microglial cell activation and, as a consequence, further progressive bystander neuronal degeneration [53]. It has been suggested that tau pathology results from elevated protein kinase activity, a reduction in the activity of protein phosphatase, or both [45]. Analysis of phosphorylated tau isolated from AD brains has identified numerous target serine or threonine residues [45]. It has been demonstrated that MAP-kinase, GSK-3 $\beta$, and/or Cdk 5 are the main kinases involved in tau phosphorylation. However, in $\mathrm{AD}$ not all tau phosphorylation events can be attributed to these kinases [45].

The mechanism by which tau exerts its neuronal toxicity is still controversial [54]. It has been suggested that a series of degenerative signals such as $\mathrm{A} \beta$ aggregation, iron overload [55], oxygen free radicals [56], cholesterol levels in neuronal rafts, LDL species [57], and homocysteine can activate the innate immune response [53]. The activation of microglial cells, for instance, results in the subsequent release of pro-inflammatory cytokines that modify neuronal behaviour through anomalous signalling cascades, with the end result being the promotion of tau hyperphosphorylation [53]. However, numerous cellular and transgenic animal models indicate that tau is crucial for $\mathrm{A} \beta$-induced neurotoxicity [54]. For instance, cultured hippocampal neurons from tau deficient mice are protected against $\mathrm{A} \beta$ pathology [54]. Furthermore, in cultured hippocampal neurons from wild-type mice, the silencing of tau by siRNA has demonstrated that tau is required for prefibrillar $\mathrm{A} \beta$-induced microtubule disassembly. Furthermore, it was demonstrated that a reduction in soluble $\mathrm{A} \beta$ and tau but not $\mathrm{A} \beta$ alone causes cognitive decline in the triple transgenic AD mouse model with plaques and tangles [58]. These data suggest that although $\mathrm{A} \beta$ is the initial trigger, tau accumulation plays a central role in neurodegeneration. Finally, in the AD-like transgenic model that expresses human APP with familial mutations, suppression of endogenous tau prevented $\mathrm{A} \beta$ dependent water maze learning and memory deficits without reversing the amyloid pathology [58]. Collectively, these data 

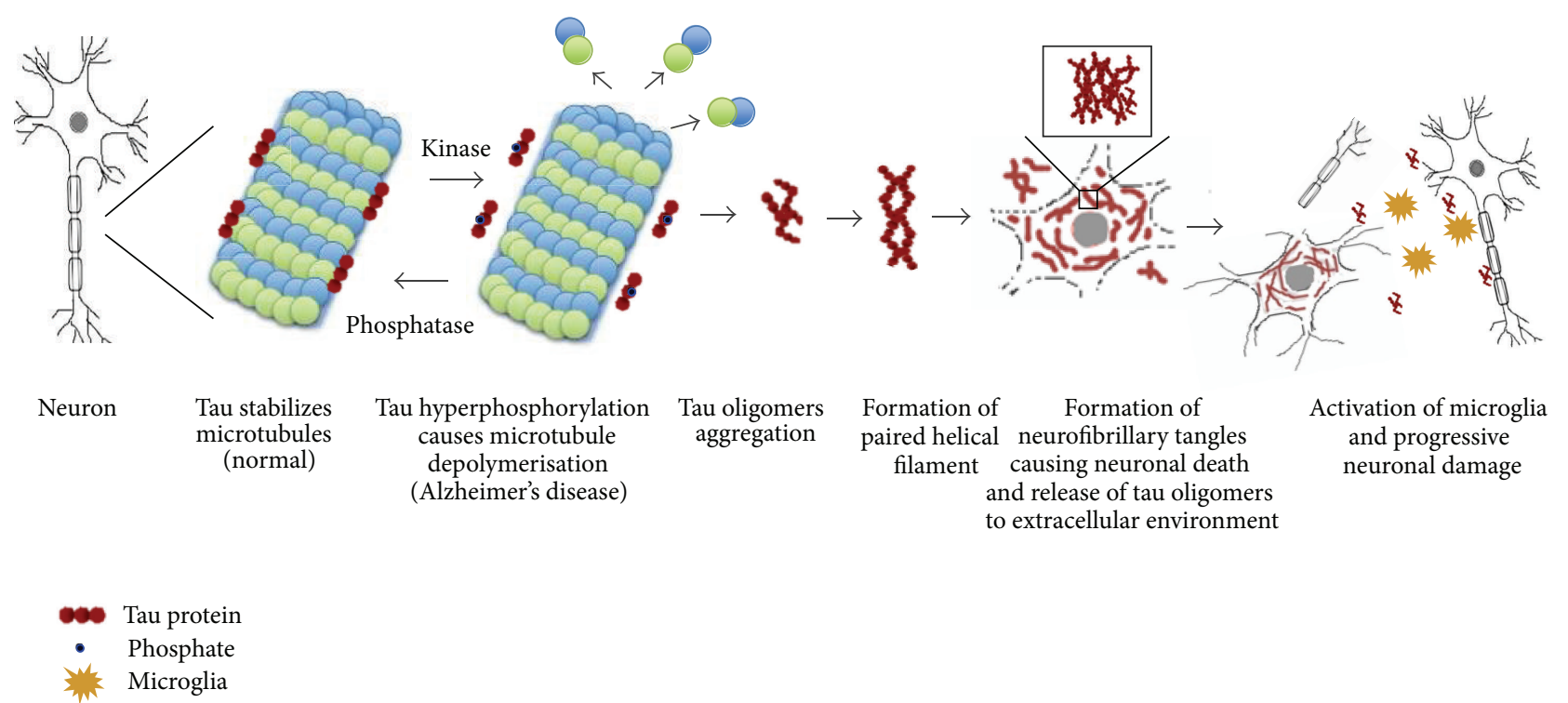

Figure 2: Stabilisation of microtubules by the tau protein is regulated by kinases and phosphatases. Abnormal hyperphosphorylation of tau proteins causes catastrophic microtubule depolymerisation and the formation of insoluble cytoplasmic tau oligomers, which aggregate to form protomers. Two protomers twisted around each other to form paired helical filaments (PHFs), which assemble to produce neurofibrillary tangles (NFTs).

suggest a link between $\mathrm{A} \beta$ and tau that drive the neural pathologies and the manifestations of clinical symptoms. Preliminary data on the inhibition of tau aggregation by methylene blue chloride (MTC) has indicated a lower rate of cognitive decline in treated patients compared with those sporadic $\mathrm{AD}$ patients on alternate therapies, implicating tau as the key initiator of cognitive deficits [50]. However, the exact role of $\mathrm{A} \beta$ dependent in signal transduction cascades that are associated with pathogenic tau modifications and the contribution to the progression of neuronal death require further investigation [54].

\section{Signalling Molecules Linked with Neuronal Cytoskeleton Disassembly}

5.1. Rho Kinase (ROCK). The Rho-associated coiled-coil forming protein kinases (ROCKs) include the ROCK-1 and ROCK-2 isoforms. These two kinases contain highly conserved aminoterminal but different carboxy-terminal domains [59]. Both ROCK-1 and ROCK-2 were originally shown to be involved in cell differentiation, essential for the regulation of myogenesis from embryonic fibroblasts along with skeletal muscle maturation and differentiation [60]. Both Rho kinase (ROCKs) and p21-activated kinase (PAKs) are members of the serine/threonine class of protein kinases. However, they are known to have antagonistic effects on the actin cytoskeleton and therefore on the plasticity of synapses. PAK also has two major isoforms, PAK1 and PAK3, and they have downstream signalling effects on Rho/Rac (for review see [61]). PAK can stimulate actin polymerisation [62], axon outgrowth, and the formation of dendritic spines [63] through LIM kinase stimulation [62]. PAK can also inhibit the myosin light chain kinase (MLCK) which diminishes actomyosin contractility $[64,65]$.

It has been reported that 13 -month-old $\mathrm{AD}$-like mice (PDAPP) displayed a substantial decrease in PAK 1-3 activity compared to normal controls [21]. Furthermore, the hippocampi of patients exhibiting the early clinical signs of AD have displayed high PAK 1-3 activity which was then shown to decline in the late stages of $\mathrm{AD}$ pathology [21]. It was further suggested that C-terminal cleavage of APP at the Asp664 site mediates PAK abnormalities and that an Asp664 mutation may potentially prevent these abnormalities [21]. On the other hand, ROCKs stimulate the retraction of axonal and dendritic growth cones by activating MLCK through the phosphorylation of myosin light chain proteins to promote an interaction with actin [66]. In addition, ROCK2 can phosphorylate collapsin response mediator protein 2 (CRMP2), another microtubule associated protein, to induce growth cone collapse [67].

Moreover, many developmentally or pathologically regulated molecules can also activate the RhoA/ROCK pathway to inhibit axonal growth including semaphorins, ephrins, and myelin inhibitory factors, such as Nogo and myelinassociated glycoprotein (MAG). On the other hand, there are some signalling molecules such as Sema4D/plexin-B1 that activate the RhoA/ROCK pathway especially in hippocampal neurons that may induce dendritic spine formation. It has been speculated that this may be due to the activation of LIM kinase and the PAK-type response via actin-depolymerising factor ADF/cofilin [68, 69].

In $\mathrm{AD}$, dendritic spine defects play a major role in cognitive impairments [61]. It has been reported that dendritic postsynaptic proteins are excessively distorted with disease progression [70]. For instance, neuronal loss in the 


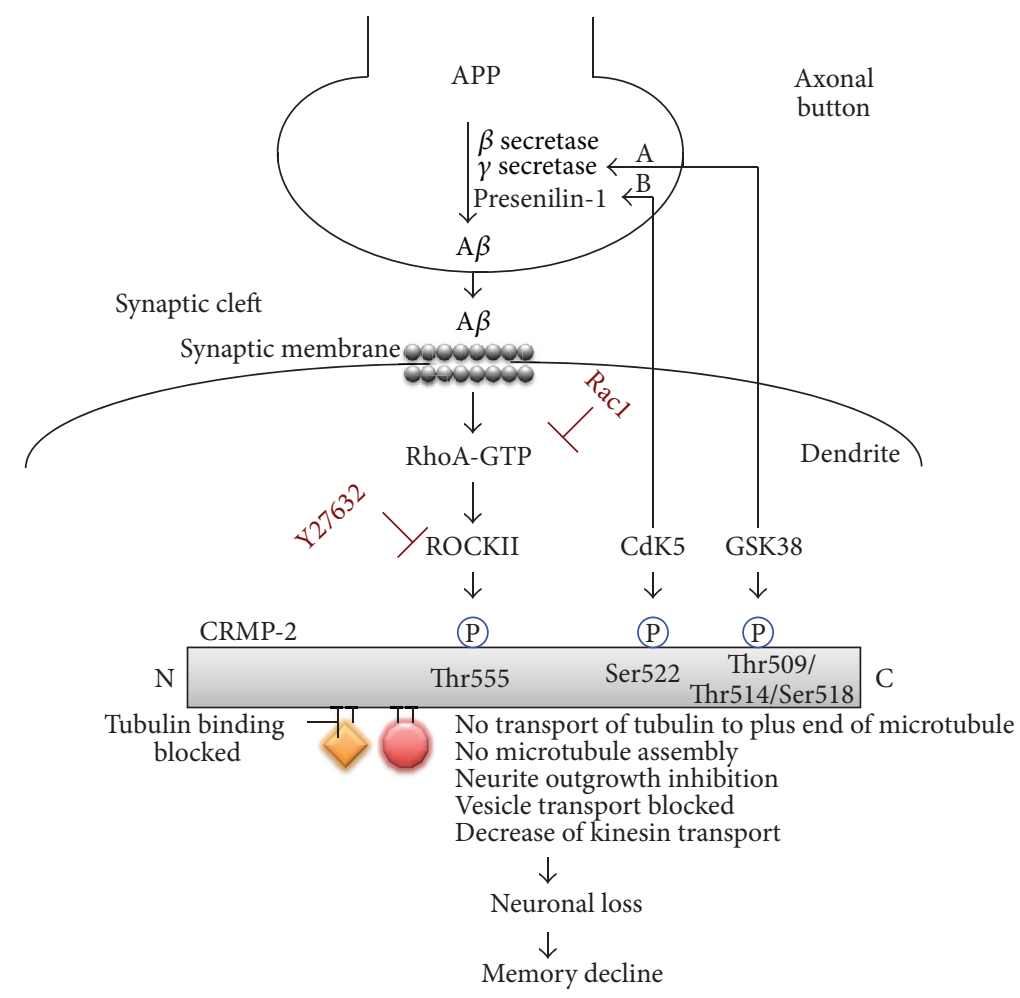

Tubulin

Kinesin

FIgUre 3: Model of $\mathrm{A} \beta$-mediated neurite outgrowth inhibition. $\mathrm{A} \beta$ (oligomeric) activates the small GTPase, RhoA, which inhibits the proneurite outgrowth GTPase Racl. RhoA-GTP activates Rho Kinase (ROCK II) to effect microfilament rearrangement and also potentiate microtubule disassembly. Microtubule disassembly occurs when ROCK II directly phosphorylates CRMP-2 at the Thr555 position preventing the association of CRMP-2 with tubulin heterodimers, thereby affecting neurite outgrowth inhibition. Neurite outgrowth is further impeded by CRMP-2 phosphorylation since this prevents the microtubule motor protein, kinesin, to associate with CRMP-2 and transport growthrelated vesicular cargo, such as BDNF, antergradely to the distal end of the neurite. It is demonstrated that CRMP- 2 is also phosphorylated by GSK-3 $\beta$ and Cdk-5. (A) Studies have demonstrated that GSK-3 $\beta$ activity can also regulate the processing of APP resulting in the production of $\mathrm{A} \beta$, which in turn can further increase GSK-3 $\beta$ activity through PI3K inhibition, illustrating as a potential feedback loop. (B) Additionally, it has been suggested that Cdk5 may phosphorylate presenilin-1 at Thr354 destabilising its carboxy-terminal fragment, leading to increased APP processing.

hippocampi of $\mathrm{AD}$ patients is approximately $5-40 \%$ while the loss of postsynaptic proteins such as the developmentally regulated actin-regulating brain protein (drebrin), which is targeted by $\mathrm{A} \beta$ oligomers, reaches $70-95 \%$ [71]. This study in particular suggested that $\mathrm{A} \beta$-induced alteration in postsynaptic PAK may have a central role in the massive drebrin loss and cognitive deficits found in $\mathrm{AD}$, which could be prevented by an antibody to $\mathrm{A} \beta$ and/or by in vivo or in vitro overexpression of wild-type PAK [71].

Cognitive defects and eventually dementia are important clinical features of $\mathrm{AD}$ (for review see [2]). It has been reported that there exists a relationship between the cognitive-decline occurring in $\mathrm{AD}$ along with genetic mental retardation syndromes and synaptic dysfunction, primarily since the postsynaptic maintenance of dendritic spines is lost. To maintain synaptic balance, both ROCK1 and 2 transduce signals to retract the growth cones and dendritic spines (for review see [72]). It has been shown that ROCK may provoke
APP breakdown to the toxic $\beta$-amyloid 1-42 peptide. For example, ROCK inhibitors, such as Y27632, inhibit the toxic processing of APP [73]. An intriguing conundrum is that the binding of $A \beta$ on neurons may activate RhoA and ROCK2 to potentiate the phosphorylation of its substrates $[74,75]$. One of the specific substrates that our group has recently defined is CRMP-2 (Figure 3). It has been shown that CRMP-2 exhibits hyperphosphorylation in the cortex of $\mathrm{AD}$ postmortem brains [76]. Experimentally, it has been illustrated that other kinases such as GSK-3 and Cdk5 can also phosphorylate CRMP-2 and produce growth cone collapse in neurons [77] (Figure 3). Our data suggest that $\beta$-amyloid can increase the RhoA-GTP level in differentiated SH-SY5Y cells increasing CRMP-2 phosphorylation and reducing the neurite lengths in cultured neuroblastoma cells. Additionally, RhoA and CRMP-2 levels are elevated in neurons surrounding amyloid plaques in the cerebral cortex of the APP (Swe) Tg2576 $\mathrm{AD}$ mouse model. Our work indicates that $\mathrm{A} \beta$ induces 
Rho GTPase activity and ROCK2 to promote CRMP-2 phosphorylation which can lead to the inhibition of neurite outgrowth [78] (Figure 3). However, a direct link with the reduction of ROCK2-dependent CRMP-2 phosphorylation and the limitation of cognitive decline is yet to be established in the context of $\mathrm{A} \beta$-dependent neurodegeneration.

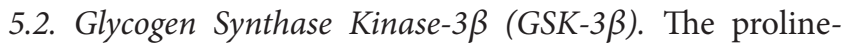
directed serine/threonine kinase, glycogen synthase kinase3 (GSK-3), is important for several cellular processes such as metabolism, cell structure, and apoptosis and in the regulation of gene expression (for review see [79]). The GSK-3 family contains two members, GSK- $3 \alpha$ and GSK- $3 \beta$, that are highly expressed in the brain and spinal cord with GSK-3 $\beta$ playing a central role in neuronal differentiation and the maintenance of neurons (for review see [80]). Activation of GSK-3 requires prephosphorylation by other priming kinases such as Cdk5 at serine or threonine sites located 4 residues, C-terminal to the site phosphorylated by GSK-3 (for review see [81]) (Figure 3). Abnormal GSK-3 function has been implicated in different brain pathologies indicating its fundamental role in controlling basic mechanisms of neuronal function, modulation of neuronal polarity, migration, proliferation, and survival, not to mention the establishment of neuronal circuits (for review see [82]). It has been demonstrated that phosphorylation of GSK-3 may influence cytoskeletal proteins altering neuronal plasticity (for review see [83]). Neuronal cytoskeletal changes occur due to an altered rate in the stabilisation/destabilisation of microtubules (MT), thereby altering the dynamics of dendrites, spines, axons, and synapses. Intensified efforts in the identification of enzymes involved in regulating tau phosphorylation in vivo have revealed GSK-3 $\beta$ as a candidate kinase for therapeutic targeting [79] during $\mathrm{AD}$ pathology.

It has been hypothesised that GSK-3 overactivity may potentiate sporadic and familial forms of $\mathrm{AD}$ by enhancing tau hyperphosphorylation [84] and APP processing and possibly through the phosphorylation of CRMP-2 leading to profound memory impairment [81] (Figures 2 and 3). It has been established that the expression of full-length unmodified or unphosphorylated CRMP-2, in primary hippocampal neurons or SH-SY5Y neuroblastoma cells, promotes axon elongation. Moreover, cultured neurons expressing CRMP2 with mutant GSK-3 phosphorylation sites (T509A, S518A) display significantly reduced axon elongation [81]. On the other hand, studies have demonstrated that GSK-3 $\beta$ phosphorylation of the CRMP-2 T509 site can play a crucial role in mediating the repulsive action of Sema3A [85] and promoting growth cone collapse [77]. Recently, Cole et al. have demonstrated that dephosphorylation of CRMP2 at the GSK-3 $\beta$-dependent sites (Ser-518/Thr-514/Thr-509) can be carried out by a protein phosphatase 1 (PP1) in vitro, observed in neuroblastoma cells and primary cortical neurons, and that the inhibition of GSK- $3 \beta$ by insulin-like growth factor-1 or the highly selective inhibitor CT99021 results in dephosphorylation of CRMP-2 at these sites [86]. How this may be translated to real therapeutic outcomes during $\mathrm{AD}$ pathology is yet to be demonstrated, even within animal models of disease.
5.3. Cyclin-Dependent Kinase-5 (Cdk5). The other prolinedirected serine/threonine kinase, identified as a major priming enzyme for tau phosphorylation, is cyclin-dependent kinase-5 (Cdk5) [87]. Although Cdk5 is ubiquitously expressed in most tissues, it is not directly involved in mediating progression through the cell cycle as it requires prior activation by $\mathrm{p} 35$ and $\mathrm{p} 39$, which are expressed almost exclusively in the CNS [88]. Cdk5 plays an important role in CNS development possibly by mediating interactions between neurons and glia during radial migration, which is essential for developing appropriate cortical laminar architecture $[89,90]$. Furthermore, Cdk5 has been reported to also play a role in neuronal differentiation, axonal guidance, synaptic plasticity, cellular motility, cellular adhesion, and neurodegeneration (for review see [91]).

Studies have shown that inhibition of Cdk5 reduces $A \beta$ induced neurodegeneration in cortical neurons [92] which highlights that targeting Cdk5 could be a future therapeutic strategy for neurodegenerative disorders. The critical microtubule associated protein, CRMP-2, has been also demonstrated to be a substrate for Cdk5 [77]. This study showed an orderly phosphorylation process of CRMP-2 by Cdk 5 (defining it as the priming kinase) followed by GSK-3 $\beta$ as a consequence of Sema3A stimulation that inhibits axonal growth [77]. Alternatively, a non-phosphorylated form of CRMP-2 cannot respond to Sema3A signalling. This study also demonstrated that Sema3A promotes phosphorylation of CRMP-2 at Ser522, which is the established Cdk5 phosphorylation site [77]. Thus, targeted kinase inhibitors may possibly be therapeutically beneficial in $\mathrm{AD}$ to limit both tau and CRMP-2 phosphorylation. Deciphering which of the kinases precipitate neurodegeneration is still under investigation but when elucidated, the possibility exists that formulation of specific inhibitors to prevent cognitive decline associated with $\mathrm{AD}$ is achievable.

5.4. Phosphatases. Protein phosphatases provide unique endogenous signalling mechanisms for the dephosphorylation of proteins, reversing such posttranslational modifications, which may limit protein dysfunction. Protein phosphatase 2A (PP2A) is one of the most important serine/threonine phosphatases in the mammalian brain. It also exists in most tissues comprising up to $1 \%$ of total cellular protein. It has major roles in development, cell growth, transformation (for review see [3]), regulation of protein phosphorylation, and cell signalling pathways [93]. PP2A is composed of 3 subunits: subunit A (scaffolding/structural), subunit B (regulatory/targeting), and subunit C (catalytic) [94]. PP2A with PP1 collectively account for more than $80 \%$ of the total serine/threonine phosphatase activity in all mammalian cells $[3,95]$ making these enzymes integral to cellular physiology.

In situ, PP2A, PP1, PP5, and PP2B account for $71 \%$, $11 \%, 10 \%$, and $7 \%$, respectively, of the total tau phosphatase activity in the human brain [96]. PP2A is the most prevalent phosphatase involved in tau dephosphorylation [97]. Knockdown of PP2A phosphatase activity was shown to lead to tau hyperphosphorylation [98]. Furthermore, when PP2A was inhibited in cultured cells and in transgenic mice with mutant 
PP2A, hyperphosphorylation of tau was observed [98]. Moreover, the naturally abundant SET protein, a potent PP2A inhibitor, is found to be elevated in AD brains [99], possibly illustrating reduced PP2A activity allowing for the hyperphosphorylation of cellular substrates to occur unabated and the potentiation of neurodegeneration. Interestingly, autopsy studies of brains from AD patients, non-AD dementia, and normal human brains demonstrate that there is loss in PP2A protein, mRNA, and enzymatic activity in areas of the brain affected by $\mathrm{AD}$, the hippocampus and cortex, but not in the cerebellum [100]. In addition, the inhibition of PP2A activity mimics most of the phosphorylation events seen in $\mathrm{AD}$, such as tau hyperphosphorylation [101].

Phosphorylation of APP by an array of kinases has been shown to influence its cleavage by $\beta$-secretase resulting in $\mathrm{A} \beta$ production [102]. It was demonstrated that PP2A has the ability to dephosphorylate APP at the Thr668 site and thus inhibit A $\beta$ generation [103]. Studies of cells expressing the (APPswe) mutation, transgenic mice expressing both APPswe and presenilin mutations, and sections of hippocampus and entorhinal cortex from human AD patients, show that PP2A levels are decreased and Y307 levels (an inhibitor of PP2A) were increased [104] implying that the phosphatase affects the processing of APP and highlighting its importance in limiting $\mathrm{AD}$ pathology. In $\mathrm{N} 2 \mathrm{a}$ cells, where $\mathrm{PP} 2 \mathrm{~A}$ was inhibited with okadaic acid (OA), the phosphorylation of APP and the secretion of both $\operatorname{sAPP} \alpha$ and $\operatorname{sAPP} \beta$ were all elevated [105]. In addition, inhibition of the protein phosphatases PP1 and $\mathrm{PP} 2 \mathrm{~A}$ in rat brain by $\mathrm{OA}$ results in the accumulation of hyperphosphorylated tau and $\mathrm{A} \beta$ species $[45,94]$. Even though incubation of different types of cells with OA resulted in the stimulation of APP secretion, it was not proven that the effect was mediated by PP1 [106] and/or PP2A [107]. Moreover, it was demonstrated that demethylation of PP2A by nuclear phosphatase methylesterase-1 (PME-1) reduces its activity and thus leads to tau hyperphosphorylation along with APP phosphorylation, promoting APP cleavage and A $\beta$ production [108-110]. Collectively, these results suggest that downregulation of $\mathrm{PP} 2 \mathrm{~A}$ may induce $\mathrm{A} \beta$ production and tau phosphorylation, precipitating $\mathrm{AD}$ pathology.

A direct link of PP2A activity with the progression of $\mathrm{AD}$ pathology has been affiliated to the fact that CRMP2 phosphorylation may actually be a result of lowered PP2A activity [93]. Since CRMP-2 hyperphosphorylation was commonly observed to correspond with progressive neurodegeneration, decreased PP2A may well regulate such a disease-specific event. However, such a hypothesis would need to be substantiated beyond a causal link.

5.5. Collapsin Response Mediator Protein (CRMP). The collapsin response mediator proteins (CRMPs) are members of the dihydropyrimidinase-related neuronal phosphoprotein family [111]. The CRMP family has five isoforms, CRMP15 [112]. The most well characterised of these, CRMP-2, is highly expressed in the adult mammalian CNS localising in the cytoplasm and neurites of postmitotic neurons [111]. CRMP-2 is also highly expressed in the areas of the adult brain of greatest plasticity such as the hippocampus, olfactory bulb, and cerebellum [113]. In neurons, CRMP-2 is concentrated within the distal portions of neurites, in synapses and in growth cones [114]. It regulates the polarity and differentiation of neurons through the assembly and trafficking of microtubules [115]. CRMP-2 has no known enzymatic activity by itself but through an interaction with other binding partners it can regulate neural differentiation, dendrite/axon fate specification, $\mathrm{Ca}^{2+}$ homeostasis, neurotransmitter release, regulation of cell surface receptor endocytosis, kinesin-dependent axonal transport, growth cone collapse, neurite outgrowth, and microtubule dynamics (for review see $[78,116]$ ). The last three functions have been demonstrated to be regulated by phosphorylation near the $\mathrm{C}$ terminus of CRMP-2 by kinases $[117,118]$ including cyclindependent kinase 5 (Cdk5), glycogen synthase kinase-3 $\beta$ $($ GSK-3 $\beta)$ [31, 76, 86, 119], Tau-tubulin kinase-1 (TTBK1) [120], and Rho kinase II (ROCKII) [78, 117, 121], all of which culminate in neurite retraction (for review see [78]). CRMP-2 hyperphosphorylation in AD was suggested to be a result of increased kinase activity, decreased phosphatase activity, or both [86]. All phosphorylation events can disrupt the association of mature full-length CRMP-2 with tubulin heterodimers possibly resulting in the destabilisation of the neuronal microtubule system rendering axonal retraction [67]. Moreover, disruption of the binding between CRMP-2 and tubulin due to the phosphorylation of CRMP-2 can block tubulin transport to the plus ends of microtubules for assembly (Figure 3) [78], blocking neurite outgrowth/elongation. In primary neurons and neuroblastoma cells, it has been demonstrated that overexpression of CRMP-2 results in axon elongation [114] while overexpression of truncated CRMP2, lacking the C-terminus tubulin binding domain, inhibits axon growth. These data implicate this region of CRMP2 to play a central role in axonal growth [114]. Both the Cdk5 and GSK-3 $\beta$ phosphorylation of CRMP-2 have been shown to be increased in the cortex and hippocampus of the triple transgenic mouse (PS1/APP/Tau mutant), along with the double transgenic mouse (PS1/APP mutant), that develop AD-like plaques along with NFTs. However, in transgenic mice, which display only mutant tau (P301L) that develop tangles but do not develop amyloid plaques, Cdk5 phosphorylation of CRMP-2 does not occur. These results indicate that hyperphosphorylation of CRMP-2 might be induced by APP overexpression and/or its enhanced processing, thereby generating a high amyloid load within the brain of these transgenic mice [76].

Our laboratory has recently demonstrated that, in human neuroblastoma SH-SY5Y cells and in the Tg2576 mouse model of $\mathrm{AD}, \mathrm{A} \beta$ can reduce the length of neurites by inactivating the neurite outgrowth-signalling molecule Rac1 [78]. Furthermore, the data suggested that $\mathrm{A} \beta$-mediated reduction in neurite length could be reversed by the Rho Kinase inhibitor (Y27632). Additionally, the A $\beta$-mediated decrease in neurite length was linked to the promotion of a threonine phosphorylation of CRMP-2 (unrelated to GSK-3 $\beta$-dependant phosphorylation), conferring a reduced binding capacity to tubulin, both of which can be reversed by inhibiting RhoA activity [78]. These data suggested that $\mathrm{A} \beta$-mediated neurite outgrowth inhibition results from the 
activity of RhoA-GTP and the dysregulation of CRMP-2 to bind tubulin for neurite outgrowth [78] (Figure 3).

Studies using transgenic mouse models expressing the Swedish familial AD mutant (APP/TTBK1) demonstrated that the induced upregulation of tau tubulin kinase-1 (TTBK1) can promote axonal degeneration via phosphorylation of CRMP-2 and tau within the entorhinal cortex and hippocampus, implicating TTBK1 as a potential therapeutic target for $\mathrm{AD}[120]$.

Despite the profound link to CRMP-2-dependent degeneration through kinase-mediated phosphorylation, another function of CRMP2 is mediated through its known association with kinesin, facilitating the anterograde molecular transport of growth promoting vesicles along axonal microtubules [122]. The exact mechanism of binding and transport and its contribution to $\mathrm{AD}$ will be discussed in detail below.

\section{CRMP2-Tubulin Binding}

The microtubule and actin cytoskeleton orchestrates axonal growth cone dynamics by a process of signal transduction leading to either depolymerisation or polymerisation events, for directional growth [119]. As already discussed above, the binding of CRMP2 to tubulin heterodimers can enhance microtubule assembly leading to axon outgrowth $[123,124]$. Semaphorin-3A (Sema3A) is an extracellular protein that can block axonal outgrowth [77] through the activation of Cdk5, with downstream phosphorylation of both tau and CRMP-2 [31, 77]. Such phosphorylation can disrupt their tubulin association limiting axonal growth. Following the Cdk5 phosphorylation of CRMP-2, the latter may potentiate a conformational change leading to subsequent phosphorylation by GSK-3 $\beta[31,77]$. However, it has been demonstrated that in GSK- $3 \beta$ overexpressing mice, no hyperphosphorylation of CRMP-2 can be identified at the GSK$3 \beta$ phosphorylation sites and furthermore phosphorylation of tau does not increase [125]. This may explain the finding that activation of GSK-3 $\beta$ alone can not induce growth cone collapse (for review see [119]). Interestingly, protein lysates from human $\mathrm{AD}$ cortex and animal models of $\mathrm{AD}$ show hyperphosphorylation of CRMP-2 at residues Thr509, Thr514, and Ser518 which are known to be the GSK-3 $\beta$ phosphorylation sites as well as Ser522, the well-known Cdk5 phosphorylation site (for review see [78]). These findings indicate that Sema3A signalling may regulate microtubule polymerisation through the physiological actions of tau and CRMP-2, which regulate the dynamics of microtubules and tubulin dimers, respectively [126]. Phosphorylation of CRMP-2 by Rho kinase at the Thr555 site, however, can also reduce the CRMP-2 association with tubulin heterodimers and induce growth cone collapse unrelated to Sema3A signalling and quite possibly be the result of $\mathrm{A} \beta$-dependent signalling $[31,77]$. The phosphorylation of CRMP-2 by Cdk5, GSK-3 $\beta$, and Rho kinase may therefore play a central role in coordinating cytoskeletal activities in response to multiple axon guidance cues $[31,77]$.

The plausible hypothesis exists that activation of all thre kinases Cdk5/GSK-3b/ROCK2, contribute to the destabilisation of the neuronal microtubule system in $\mathrm{AD}$.
Consequently, tau and CRMP-2 have some similarities in that both control microtubule polymerisation and stability and they both respond to the growth cone guidance molecule Sema3A [77]. Therefore, it can be theorised that a balanced treatment which may successfully decrease CRMP2 phosphorylation could also be effective in regard to tau aggregation and vice versa in $\mathrm{AD}$ (for review see [31]).

\section{Microtubules (MT)}

One of the most important physiological features of the multipolar neuron is to have a polarised axon, that can extend to more than 1 meter in the human CNS [127]. For the neuron to function normally, it should be able to transport vital molecular cargo from its body to synaptic terminals and vice versa in a timely manner through the axon via anterograde and retrograde transport mechanisms, respectively $[127,128]$. Therefore, it stands to reason that the integrity of the microtubule transport system is crucial for axonal transport [129]. The microtubule system facilitates ATP driven transport through molecular motors of the cell's vital components which include vesicles, proteins, mitochondria, chromosomes, and large macromolecules such as microtubule heterodimers themselves $[128,130]$. The transport machinery directly interacts with microtubules and includes two families of proteins categorised according to their directional movement. These proteins include either microtubule plus end-directed kinesins or the microtubule minus end-directed cytoplasmic dynein [127].

Many neurodegenerative diseases, such as $\mathrm{AD}$, display a blockade in microtubule transport, emphasising its significance in normal physiology and highlighting abnormal neuronal vesicle trafficking as a potential pathogenic mechanism [130-132]. It is believed that $A \beta$ may cause mitochondrial dysfunction and, therefore, axonal transport defects [132]. It has been demonstrated that APP processing and $\mathrm{A} \beta$ overproduction in the mitochondria lead to mitochondrial dysfunction and therefore reduction of mitochondrial energy supply and inhibition of axonal transport [133]. Enhancing energy supply of neurons could be critical to compensate for the $\mathrm{A} \beta$-dependent loss of energy and thus facilitate axonal transport.

Microtubule depolymerisation has been touted as a contributing factor in the gross loss of memory, as it is necessary to stabilise newly formed microtubules in spines for longlasting memory $[134,135]$. There exists evidence implicating tubulin sequestration [136] and blockade in microtubule assembly as a pathogenic mechanism of $\mathrm{AD}$ [129]. It has been recently demonstrated that in vitro, microtubules can be assembled from the cytosol of normal autopsy brain obtained within five hours postmortem, while this is not possible from identically treated AD postmortem brain tissue [129]. Furthermore, it has been documented that axonal transport is defective in neurons from $\mathrm{AD}$ postmortem brains indicating the destruction of the microtubule cytoskeleton in axons of diseased neurons [134]. There also exist data suggesting that the abnormality in axonal transport might stimulate the formation of, or enhance the accumulation of, $\mathrm{A} \beta[134,137]$, 
through autophagocytosis of mitochondria without normal lysosomal degradation [137].

One of the main physiological functions of tau is to stimulate microtubule assembly by polymerising with tubulin, maintaining the microtubule structure and stability through its capacity to anchor polymerised microtubules to the internal axolemma [129]. Evidence for the role of tau and microtubule destabilisation arises from tau transgenic mice which show spinal cord tau inclusions [131]. In this animal model, an inability of tau to stabilise microtubules can be compensated with the MT-stabilising agent paclitaxel resulting in increased MT density and marked improvement in motor function [131]. However, paclitaxel is thought to have poor blood-brain barrier permeability and thus is an unlikely candidate for human therapy during neurodegeneration [131].

In the early stages of $\mathrm{AD}$ pathogenesis, observations within the neuropil demonstrate that there exists an abnormal aggregation of the activated actin-associated protein cofilin, a protein that modulates actin-rich dendritic spine architecture, which is important for learning and memory [43]. Those neuropil threads can disrupt the cytoskeletal network by blocking cargo trafficking to synapses, resulting in memory and cognition impairment [43]. It is also suggested that abnormal activation of cofilin may trigger the accumulation of phosphorylated tau in neuropil threads [43]. The activities of cofilin and the protein actin-depolymerising factor (ADF) are regulated by phosphorylation and dephosphorylation through LIM and other kinases, along with chronophin phosphatases, respectively [43]. Heredia et al. found that $\beta$ amyloid may activate LIMK1 and thus stimulate ADF/cofilin phosphorylation in cultured neurons [69]. Moreover, they demonstrated, in the $\mathrm{AD}$ brain, that the number of $\mathrm{P}$ LIMK1-positive neurons was extensively increased in the affected regions [69]. A recent study of AD transgenic mice demonstrated that neuronal cell bodies are viable although the neurites are damaged [138]. Taken together, these studies highlighted that the development of in vivo methods to disrupt LIMK1 activation, the formation of the cofilin-actin rods, and/or the interaction between cofilin and pMAP, may be a plausible way to stop the disease early in its presentation.

\section{Kinesin}

The microtubule motor protein complex, kinesin-1, has a fundamental role in the vesicular transport from the neuronal cell body, along the axon and anterograde, to the synapse (for review see [139]). The motor protein complex consists of two kinesin heavy chains (KHC) that have both an ATP and the microtubule binding motif which are essential for vesicle transport [140]. Two kinesin light chains (KLC) that associate with the heavy chain and vesicular cargo membranes [140] complete the structure of the transport protein. APP is one of the molecular candidates for receptors that attach kinesin-1 to vesicular cargo [139]. The carboxy terminus of APP binds directly to the light-chain subunits of kinesin$1[140]$ and thus plays a major role in the recruitment of kinesin-1 to axonal vesicles [141]. Moreover, the level of axonal APP is suggested to play a central role in determining expression levels of kinesin-1 decorating vesicles, providing the ability to determine the anterograde movement behaviour of APP-containing vesicles [141]. It has been reported that kinesin blockade and axonal swellings are involved in the pathogenesis of the early stages of $\mathrm{AD}$ even before the formation of amyloid plaques and neurofibrillary tangles, although the initiating events are not clear [142]. Moreover, in animal models, $\beta$-amyloid formation and its subsequent transport are enhanced when kinesin transport is abrogated or impaired $[38,141]$. Axonal transport damage results in the development of axonal swellings where APP is processed into smaller $\mathrm{A} \beta$ species. APP axonal transport is mediated by direct binding to KLC1 [143]. Genetic manipulation designed to damage APP axonal transport in AD mouse models, such as Tg-swAPP ${ }^{\operatorname{Prp}}$, demonstrated the enhancement in the incidence of axonal swellings, elevated $\mathrm{A} \beta$ levels, and potentiated the production of amyloid deposition [142]. In particular, APP directly interacts with KLC1 (the microtubule transport machinery) through its carboxy terminus, suggesting that impaired interaction of APP and KLCl might play a central role in the AD pathogenesis [144]. Decreased KLC1 transport may also stimulate tau hyperphosphorylation and formation of NFTs as well as axonal swellings producing catastrophic damage to axons. Such damage may arise from increased $\mathrm{A} \beta$ levels and tau hyperphosphorylation, further disrupting axonal transport [145].

It is now well established that CRMP-2 plays a central role in negotiating fast axonal transport by acting as an adaptor protein to the microtubule motor kinesin-1, for propagation of anterograde vesicle transport of key traffic molecules such as the high affinity neurotrophin receptor, tyrosine kinase (TrkB). Following distal localisation of this receptor, TrkB is inserted into the cell membrane and activated by its cognate ligand brain-derived neurotrophic factor (BDNF), resulting in axonal growth through signalling within the growth cone, thereby establishing the accumulation and polymerisation of F-actin and tubulin. In AD, phosphorylated CRMP-2 releases kinesin-1, inhibiting TrkB function and limiting the structural integrity of the actin-based cytoskeleton in distal axons, growth cones, and synapses [146]. Inhibiting CRMP2 phosphorylation could be beneficial to restore tubulin and kinesin-1 binding to CRMP-2 and thus promoting axonal outgrowth and transport of important molecular cargo.

\section{Conclusion}

Alzheimer's disease (AD) is an age-related progressive neurodegenerative disorder and is the most common form of dementia in the elderly. The hallmarks of AD pathology are the extracellular deposition of a $4 \mathrm{kDa}$ amyloid beta $(\mathrm{A} \beta)$ polypeptide and the formation of intracellular neurofibrillary tangles (NFTs) along with dystrophic neurites, degenerating neurons, and activated astrocytes and microglia, a part of the reactive pathology observed around senile plaques. Neuritic plaques result from the aggregation of the amyloid $\beta$ protein $(\mathrm{A} \beta)$ which is a consequence of amyloid precursor protein (APP) aberrant processing. The corresponding accumulation of filamentous inclusions within the CNS as neurofibrillary 
tangles (NFTs), resulting from the hyperphosphorylation of the microtubule-associated protein, tau and amyloid deposition, are both pathognomonic to sporadic AD. There is an impressive list of genes and proteins involved in $\mathrm{AD}$ pathologies including APP, presenilins, secretases, kinases, and phosphatases all touted as being responsible for either increasing the production of the neurotoxic $A \beta$ protein or promoting the hyperphosphorylation of CRMP-2 or tau, leading to the devastating neurodegenerative sequelae. The understanding of the major gene players cooperating with key environmental factors that contribute to the manifestation of $\mathrm{AD}$ pathology is fundamental in the derivation of a more comprehensive understanding of $\mathrm{AD}$ pathogenesis and for the development of specific and more effective treatments of this devastating age-dependent disease.

\section{Conflict of Interests}

The authors declare that there is no conflict of interests regarding the publication of this paper.

\section{Acknowledgments}

Sara Mokhtar was supported by King Abdul-Aziz University postgraduate scholarship; Steven Petratos was supported by National Multiple Sclerosis Society (USA) Project Grant ID no. RG43981/1.

\section{References}

[1] H. Kozlowski, M. Luczkowski, M. Remelli, and D. Valensin, "Copper, zinc and iron in neurodegenerative diseases (Alzheimer's, Parkinson's and prion diseases)," Coordination Chemistry Reviews, vol. 256, no. 19-20, pp. 2129-2141, 2012.

[2] P. Kumar, K. Pradhan, R. Karunya, R. K. Ambasta, and H. W. Querfurth, "Cross-functional E3 ligases Parkin and C-terminus Hsp70-interacting protein in neurodegenerative disorders," Journal of Neurochemistry, vol. 120, no. 3, pp. 350-370, 2012.

[3] R. Liu and J. Wang, "Protein phosphatase 2A in Alzheimer's disease," Pathophysiology, vol. 16, no. 4, pp. 273-277, 2009.

[4] L. Crews, E. Rockenstein, and E. Masliah, "APP transgenic modeling of Alzheimer's disease: mechanisms of neurodegeneration and aberrant neurogenesis," Brain Structure and Function, vol. 214, no. 2-3, pp. 111-126, 2010.

[5] S. Przedborski, M. Vila, and V. Jackson-Lewis, "Neurodegeneration: what is it and where are we?" Journal of Clinical Investigation, vol. 111, no. 1, pp. 3-10, 2003.

[6] K. C. Chan, K. X. Cai, H. X. Su et al., "Early detection of neurodegeneration in brain ischemia by manganese-enhanced MRI," in Proceedings of the IEEE Conference on Engineering in Medicine and Biology Society, pp. 3884-3887, 2008.

[7] D. Selkoe, E. Mandelkow, and D. Holtzman, "Deciphering Alzheimer disease," Cold Spring Harbor Laboratory Press, vol. 2, no. 1, Article ID a011460, 2012.

[8] M. Morimatsu, S. Hirai, A. Muramatsu, and M. Yoshikawa, "Senile degenerative brain lesions and dementia," Journal of the American Geriatrics Society, vol. 23, no. 9, pp. 390-406, 1975.

[9] S. S. Sisodia, E. H. Koo, K. Beyreuther, A. Unterbeck, and D. L. Price, "Evidence that $\beta$-amyloid protein in Alzheimer's disease is not derived by normal processing," Science, vol. 248, no. 4954, pp. 492-495, 1990.

[10] D. A. Kirschner, C. Abraham, and D. J. Selkoe, "X-ray diffraction from intraneuronal paired helical filaments and extraneuronal amyloid fibers in Alzheimer disease indicates cross- $\beta$ conformation," Proceedings of the National Academy of Sciences of the United States of America, vol. 83, no. 2, pp. 503-507, 1986.

[11] F. S. Esch, P. S. Keim, E. C. Beattie et al., "Cleavage of amyloid $\beta$ peptide during constitutive processing of its precursor," Science, vol. 248, no. 4959, pp. 1122-1124, 1990.

[12] T. G. Williamson, S. S. Mok, A. Henry et al., "Secreted glypican binds to the amyloid precursor protein of Alzheimer's disease (APP) and inhibits APP-induced neurite outgrowth," Journal of Biological Chemistry, vol. 271, no. 49, pp. 31215-31221, 1996.

[13] D. H. Small, T. Williamson, G. Reed et al., "The role of heparan sulfate proteoglycans in the pathogenesis of Alzheimer's disease," Annals of the New York Academy of Sciences, vol. 777, pp. 316-321, 1996.

[14] D. H. Small, V. Nurcombe, G. Reed et al., "A heparin-binding domain in the amyloid protein precursor of Alzheimer's disease is involved in the regulation of neurite outgrowth," Journal of Neuroscience, vol. 14, no. 4, pp. 2117-2127, 1994.

[15] W. Q. Wei, A. Ferreira, C. Miller, E. H. Koo, and D. J. Selkoe, "Cell-surface $\beta$-amyloid precursor protein stimulates neurite outgrowth of hippocampal neurons in an isoform-dependent manner," Journal of Neuroscience, vol. 15, no. 3, pp. 2157-2167, 1995.

[16] I. Ohsawa, Y. Hirose, M. Ishiguro, Y. Imai, S. Ishiura, and S. Kohsaka, "Expression, purification, and neurotrophic activity of amyloid precursor protein-secreted forms produced by yeast," Biochemical and Biophysical Research Communications, vol. 213, no. 1, pp. 52-58, 1995.

[17] E. A. Milward, R. Papadopoulos, S. J. Fuller et al., "The amyloid protein precursor of Alzheimer's disease is a mediator of the effects of nerve growth factor on neurite outgrowth," Neuron, vol. 9, no. 1, pp. 129-137, 1992.

[18] L. W. Jin, H. Ninomiya, J. Roch et al., "Peptides containing the RERMS sequence of amyloid $\beta / A 4$ protein precursor bind cell surface and promote neurite extension," Journal of Neuroscience, vol. 14, no. 9, pp. 5461-5470, 1994.

[19] K. C. Breen, M. Bruce, and B. H. Anderton, "Beta amyloid precursor protein mediates neuronal cell-cell and cell-surface adhesion," Journal of Neuroscience Research, vol. 28, no. 1, pp. 90-100, 1991.

[20] B. Allinquant, P. Hantraye, P. Mailleux, K. Moya, C. Bouillot, and A. Prochiantz, "Downregulation of amyloid precursor protein inhibits neurite outgrowth in vitro," Journal of Cell Biology, vol. 128, no. 5, pp. 919-927, 1995.

[21] T. V. V. Nguyen, V. Galvan, W. Huang et al., "Signal transduction in Alzheimer disease: p21-activated kinase signaling requires Cterminal cleavage of APP at Asp664," Journal of Neurochemistry, vol. 104, no. 4, pp. 1065-1080, 2008.

[22] S. Sinha and I. Lieberburg, "Cellular mechanisms of $\beta$-amyloid production and secretion," Proceedings of the National Academy of Sciences of the United States of America, vol. 96, no. 20, pp. 11049-11053, 1999.

[23] J. P. Anderson, Y. Chen, K. S. Kim, and N. K. Robakis, "An alternative secretase cleavage produces soluble Alzheimer amyloid precursor protein containing a potentially amyloidogenic sequence," Journal of Neurochemistry, vol. 59, no. 6, pp. 23282331, 1992. 
[24] E. M. Snyder, Y. Nong, C. G. Almeida et al., "Regulation of NMDA receptor trafficking by amyloid- $\beta$," Nature Neuroscience, vol. 8, no. 8, pp. 1051-1058, 2005.

[25] L. Mucke, E. Masliah, G. Yu et al., "High-level neuronal expression of $A \beta(1-42)$ in wild-type human amyloid protein precursor transgenic mice: synaptotoxicity without plaque formation," Journal of Neuroscience, vol. 20, no. 11, pp. 4050-4058, 2000.

[26] V. Muresan, N. H. Varvel, B. T. Lamb, and Z. Muresan, "The cleavage products of amyloid- $\beta$ precursor protein are sorted to distinct carrier vesicles that are independently transported within neurites," Journal of Neuroscience, vol. 29, no. 11, pp. 3565-3578, 2009.

[27] S. Ahlgren, G. L. Li, and Y. Olsson, "Accumulation of $\beta$ amyloid precursor protein and ubiquitin in axons after spinal cord trauma in humans: immunohistochemical observations on autopsy material," Acta Neuropathologica, vol. 92, no. 1, pp. 4855, 1996.

[28] P. Cras, M. Kawai, D. Lowery, P. Gonzalez-DeWhitt, B. Greenberg, and G. Perry, "Senile plaque neurites in Alzheimer disease accumulate amyloid precursor protein," Proceedings of the National Academy of Sciences of the United States of America, vol. 88, no. 17, pp. 7552-7556, 1991.

[29] S. S. Sisodia and R. E. Tanzi, Alzheimer's Disease. Advances in Genetics and Cellular Biology, Springer Science+Business Media LLC, New York, NY, USA, 2007.

[30] B. Chakravarthy, C. Gaudet, M. Ménard et al., "Amyloid- $\beta$ peptides stimulate the expression of the p75NTR neurotrophin receptor in SHSY5Y human neuroblastoma cells and $\mathrm{AD}$ transgenic mice," Journal of Alzheimer's Disease, vol. 19, no. 3, pp. 915-925, 2010.

[31] K. Hensley, K. Venkova, A. Christov, W. Gunning, and J. Park, "Collapsin response mediator protein-2: an emerging pathologic feature and therapeutic target for neurodisease indications," Molecular Neurobiology, vol. 43, no. 3, pp. 180-191, 2011.

[32] J. E. Donahue, S. L. Flaherty, C. E. Johanson et al., "RAGE, LRP-1, and amyloid-beta protein in Alzheimer's disease," Acta Neuropathologica, vol. 112, no. 4, pp. 405-415, 2006.

[33] G. M. Shankar, S. Li, T. H. Mehta et al., "Amyloid- $\beta$ protein dimers isolated directly from Alzheimer's brains impair synaptic plasticity and memory," Nature Medicine, vol. 14, no. 8, pp. 837-842, 2008.

[34] A. Chiarini, I. D. Pra, J. F. Whitfield, and U. Armato, "The killing of neurons by $\beta$-amyloid peptides, prions, and proinflammatory cytokines," Italian Journal of Anatomy and Embryology, vol. 111, no. 4, pp. 221-246, 2006.

[35] C. Behl, J. B. Davis, R. Lesley, and D. Schubert, "Hydrogen peroxide mediates amyloid $\beta$ protein toxicity," Cell, vol. 77, no. 6, pp. 817-827, 1994.

[36] Z. Muresan and V. Muresan, "Neuritic deposits of amyloid- $\beta$ peptide in a subpopulation of central nervous system-derived neuronal cells," Molecular and Cellular Biology, vol. 26, no. 13, pp. 4982-4997, 2006.

[37] C. R. Jack Jr., D. S. Knopman, W. J. Jagust et al., "Hypothetical model of dynamic biomarkers of the Alzheimer's pathological cascade," The Lancet Neurology, vol. 9, no. 1, pp. 119-128, 2010.

[38] E. Rodrigues, A. Weissmiller, and L. Golstein, "Enhanced $\beta$ secretase processing alters APP axonal transport and leads to axonal defects," Human Molecular Genetics, vol. 21, no. 21, pp. 4587-4601, 2012.
[39] D. P. Devanand, N. Schupf, Y. Stern et al., "Plasma A $\beta$ and PET $\mathrm{PiB}$ binding are inversely related in mild cognitive impairment," Neurology, vol. 77, no. 2, pp. 125-131, 2011.

[40] J. W. Um, H. B. Nygaard, J. K. Heiss et al., "Alzheimer amyloid- $\beta$ oligomer bound to postsynaptic prion protein activates Fyn to impair neurons," Nature Neuroscience, vol. 15, no. 9, pp. 12271235, 2012.

[41] N. Hirokawa, Y. Shiomura, and S. Okabe, "Tau proteins: the molecular structure and mode of binding on microtubules," Journal of Cell Biology, vol. 107, no. 4, pp. 1449-1459, 1988.

[42] C. W. Scott, A. B. Klika, M. M. S. Lo, T. E. Norris, and C. B. Caputo, "Tau protein induces bundling of microtubules in vitro: comparison of different tau isoforms and a tau protein fragment," Journal of Neuroscience Research, vol. 33, no. 1, pp. 19-29, 1992.

[43] I. T. Whiteman, O. L. Gervasio, K. M. Cullen et al., "Activated actin-depolymerizing factor/cofilin sequesters phosphorylated microtubule-associated protein during the assembly of Alzheimer-like neuritic cytoskeletal striations," Journal of Neuroscience, vol. 29, no. 41, pp. 12994-13005, 2009.

[44] L. Li, Z. Liu, J. Liu et al., "Ginsenoside Rd attenuates betaamyloid-induced tau phosphorylation by altering the functional balance of glycogen synthase kinase 3 beta and protein phosphatase 2A," Neurobiology of Disease, vol. 54, pp. 320-328, 2013.

[45] T. Arendt, M. Holzer, R. Fruth, M. K. Brückner, and U. Gärtner, "Phosphorylation of tau, $\mathrm{a} \beta$-formation, and apoptosis after in vivo inhibition of PP-1 and PP-2A," Neurobiology of Aging, vol. 19, no. 1, pp. 3-13, 1998.

[46] L. M. Ittner, T. Fath, Y. D. Ke et al., "Parkinsonism and impaired axonal transport in a mouse model of frontotemporal dementia," Proceedings of the National Academy of Sciences of the United States of America, vol. 105, no. 41, pp. 15997-16002, 2008.

[47] R. D. Terry, “The cytoskeleton in Alzheimer disease," Journal of Neural Transmission, no. 53, pp. 141-145, 1998.

[48] M. E. Velasco, M. A. Smith, S. L. Siedlak, A. Nunomura, and G. Perry, "Striation is the characteristic neuritic abnormality in Alzheimer disease," Brain Research, vol. 813, no. 2, pp. 329-333, 1998.

[49] L. Martin, X. Latypova, and F. Terro, "Post-translational modifications of tau protein: implications for Alzheimer's disease," Neurochemistry International, vol. 58, no. 4, pp. 458-471, 2011.

[50] B. Bulic, M. Pickhardt, E. Mandelkow, and E. Mandelkow, "Tau protein and tau aggregation inhibitors," Neuropharmacology, vol. 59, no. 4-5, pp. 276-289, 2010.

[51] S. B. Shelton and G. V. W. Johnson, "Cyclin-dependent kinase-5 in neurodegeneration," Journal of Neurochemistry, vol. 88, no. 6, pp. 1313-1326, 2004.

[52] K. Iqbal, A. D. C. Alonso, and I. Grundke-Iqbal, "Cytosolic abnormally hyperphosphorylated tau but not paired helical filaments sequester normal MAPs and inhibit microtubule assembly," Journal of Alzheimer's Disease, vol. 14, no. 4, pp. 365370, 2008.

[53] R. B. Maccioni, G. Farías, I. Morales, and L. Navarrete, "The revitalized tau hypothesis on Alzheimer's disease," Archives of Medical Research, vol. 41, no. 3, pp. 226-231, 2010.

[54] G. Amadoro, V. Corsetti, M. T. Ciotti et al., "Endogenous A $\beta$ causes cell death via early tau hyperphosphorylation," Neurobiology of Aging, vol. 32, no. 6, pp. 969-990, 2011. 
[55] M. Lavados, M. Guillón, M. C. Mujica, L. E. Rojo, P. Fuentes, and R. B. Maccioni, "Mild cognitive impairment and Alzheimer patients display different levels of redox-active CSF iron," Journal of Alzheimer's Disease, vol. 13, no. 2, pp. 225-232, 2008.

[56] C. A. Zambrano, J. T. Egaña, M. T. Núñez, R. B. Maccioni, and C. González-Billault, "Oxidative stress promotes $\tau$ dephosphorylation in neuronal cells: the roles of cdk5 and PP1," Free Radical Biology and Medicine, vol. 36, no. 11, pp. 1393-1402, 2004.

[57] K. F. Neumann, L. Rojo, L. P. Navarrete, G. Farías, P. Reyes, and R. B. Maccioni, "Insulin resistance and Alzheimer's disease: molecular links amp; clinical implications," Current Alzheimer Research, vol. 5, no. 5, pp. 438-447, 2008.

[58] E. D. Roberson, K. Scearce-Levie, J. J. Palop et al., "Reducing endogenous tau ameliorates amyloid $\beta$-induced deficits in an Alzheimer's disease mouse model," Science, vol. 316, no. 5825, pp. 750-754, 2007.

[59] O. Nakagawa, K. Fujisawa, T. Ishizaki, Y. Saito, K. Nakao, and S. Narumiya, "ROCK-I and ROCK-II, two isoforms of Rhoassociated coiled-coil forming protein serine/threonine kinase in mice," FEBS Letters, vol. 392, no. 2, pp. 189-193, 1996.

[60] R. Sordella, W. Jiang, G. Chen, M. Curto, and J. Settleman, "Modulation of Rho GTPase signaling regulates a switch between adipogenesis and myogenesis," Cell, vol. 113, no. 2, pp. 147-158, 2003.

[61] L. Zhao, Q. Ma, F. Calon et al., "Role of p21-activated kinase pathway defects in the cognitive deficits of Alzheimer disease," Nature Neuroscience, vol. 9, no. 2, pp. 234-242, 2006.

[62] M. Gorovoy, J. Niu, O. Bernard et al., "LIM kinase 1 coordinates microtubule stability and actin polymerization in human endothelial cells," Journal of Biological Chemistry, vol. 280, no. 28, pp. 26533-26542, 2005.

[63] R. H. Daniels, P. S. Hall, and G. M. Bokoch, "Membrane targeting of p21-activated kinase 1 (PAK1) induces neurite outgrowth from PC12 cells," EMBO Journal, vol. 17, no. 3, pp. 754-764, 1998.

[64] Z. M. Goeckeler, R. A. Masaracchia, Q. Zeng, T. Chew, P. Gallagher, and R. B. Wysolmerski, "Phosphorylation of myosin light chain kinase by p21-activated kinase PAK2," Journal of Biological Chemistry, vol. 275, no. 24, pp. 18366-18374, 2000.

[65] T. Chew, R. A. Masaracchia, Z. M. Goeckeler, and R. B. Wysolmerski, "Phosphorylation of non-muscle myosin II regulatory light chain by p21-activated kinase ( $\gamma$-PAK)," Journal of Muscle Research and Cell Motility, vol. 19, no. 8, pp. 839-854, 1998.

[66] G. Gallo, "Myosin II activity is required for severing-induced axon retraction in vitro," Experimental Neurology, vol. 189, no. 1, pp. 112-121, 2004.

[67] N. Arimura, N. Inagaki, K. Chihara et al., "Phosphorylation of collapsin response mediator protein-2 by Rho-kinase: evidence for two separate signaling pathways for growth cone collapse," Journal of Biological Chemistry, vol. 275, no. 31, pp. 2397323980, 2000.

[68] B. Niederöst, T. Oertle, J. Fritsche, R. A. McKinney, and C. E. Bandtlow, "Nogo-A and myelin-associated glycoprotein mediate neurite growth inhibition by antagonistic regulation of RhoA and Racl," Journal of Neuroscience, vol. 22, no. 23, pp. 10368-10376, 2002.

[69] L. Heredia, P. Helguera, S. De Olmos et al., "Phosphorylation of actin-depolymerizing factor/cofilin by LIM-kinase mediates amyloid $\beta$-induced degeneration: a potential mechanism of neuronal dystrophy in Alzheimer's disease," Journal of Neuroscience, vol. 26, no. 24, pp. 6533-6542, 2006.
[70] K. H. Gylys, J. A. Fein, F. Yang, D. J. Wiley, C. A. Miller, and G. M. Cole, "Snaptic changes in alzheimer's disease: increased amyloid- $\beta$ and gliosis in surviving terminals is accompanied by decreased PSD-95 fluorescence," American Journal of Pathology, vol. 165, no. 5, pp. 1809-1817, 2004.

[71] Q. L. Ma, F. Yang, F. Calon et al., "p21-activated kinaseaberrant activation and translocation in Alzheimer disease pathogenesis," Journal of Biological Chemistry, vol. 283, no. 20, pp. 14132-14143, 2008.

[72] A. Salminen, T. Suuronen, and K. Kaarniranta, "ROCK, PAK, and Toll of synapses in Alzheimer's disease," Biochemical and Biophysical Research Communications, vol. 371, no. 4, pp. 587590, 2008.

[73] S. Leuchtenberger, M. P. Kummer, T. Kukar et al., "Inhibitors of Rho-kinase modulate amyloid- $\beta(\mathrm{A} \beta)$ secretion but lack selectivity for A $\beta 42$," Journal of Neurochemistry, vol. 96, no. 2, pp. 355-365, 2006.

[74] M. A. Del Pozo, N. B. Alderson, W. B. Kiosses, H. Chiang, R. G. W. Anderson, and M. A. Schwartz, "Integrins regulate rac targeting by internalization of membrane domains," Science, vol. 303, no. 5659, pp. 839-842, 2004.

[75] C. Guirland, S. Suzuki, M. Kojima, B. Lu, and J. Q. Zheng, "Lipid rafts mediate chemotropic guidance of nerve growth cones," Neuron, vol. 42, no. 1, pp. 51-62, 2004.

[76] A. R. Cole, W. Noble, L. V. Aalten et al., "Collapsin response mediator protein-2 hyperphosphorylation is an early event in Alzheimer's disease progression," Journal of Neurochemistry, vol. 103, no. 3, pp. 1132-1144, 2007.

[77] Y. Uchida, T. Ohshima, Y. Sasaki et al., "Semaphorin3A signalling is mediated via sequential Cdk 5 and GSK $3 \beta$ phosphorylation of CRMP2: implication of common phosphorylating mechanism underlying axon guidance and Alzheimer's disease," Genes to Cells, vol. 10, no. 2, pp. 165-179, 2005.

[78] S. Petratos, Q. Li, A. J. George et al., "The $\beta$-amyloid protein of Alzheimer's disease increases neuronal CRMP-2 phosphorylation by a Rho-GTP mechanism," Brain, vol. 131, no. 1, pp. 90-108, 2008.

[79] C. J. Proctor and D. A. Gray, "GSK3 and p53-is there a link in Alzheimer's disease?” Molecular Neurodegeneration, vol. 5, no. 1, p. 7, 2010.

[80] W.-Y. Kim and W. D. Snider, "Functions of GSK-3 signaling in development of the nervous system," Frontiers in Molecular Neuroscience, vol. 4, p. 44, 2011.

[81] A. R. Cole, A. Knebel, N. A. Morrice et al., "GSK-3 phosphorylation of the Alzheimer epitope within collapsin response mediator proteins regulates axon elongation in primary neurons," Journal of Biological Chemistry, vol. 279, no. 48, pp. 5017650180, 2004.

[82] S. Frame and P. Cohen, "GSK3 takes centre stage more than 20 years after its discovery," Biochemical Journal, vol. 359, no. 1, pp. $1-16,2001$.

[83] P. Salcedo-Tello, A. Ortiz-Matamoros, and C. Arias, "GSK3 function in the brain during development, neuronal plasticity, and neurodegeneration," International Journal of Alzheimer's Disease, vol. 2011, Article ID 189728, 12 pages, 2011.

[84] W. Qian, J. Shi, X. Yin et al., "PP2A regulates tau phosphorylation directly and also indirectly via activating GSK-3 $\beta$," Journal of Alzheimer's Disease, vol. 19, no. 4, pp. 1221-1229, 2010.

[85] K. A. Ryan and S. W. Pimplikar, "Activation of GSK-3 and phosphorylation of CRMP2 in transgenic mice expressing APP intracellular domain," Journal of Cell Biology, vol. 171, no. 2, pp. 327-335, 2005. 
[86] A. R. Cole, M. P. M. Soutar, M. Rembutsu et al., "Relative resistance of Cdk5-phosphorylated CRMP2 to dephosphorylation," Journal of Biological Chemistry, vol. 283, no. 26, pp. 18227-18237, 2008.

[87] D. Piedrahita, I. Hernández, A. López-Tobón et al., "Silencing of CDK5 reduces neurofibrillary tangles in transgenic Alzheimer's mice," Journal of Neuroscience, vol. 30, no. 42, pp. 13966-13976, 2010.

[88] D. W. Peterson, D. M. Ando, D. A. Taketa, H. Zhou, F. W. Dahlquist, and J. Lew, "No difference in kinetics of tau or histone phosphorylation by CDK5/p25 versus CDK5/p35 in vitro," Proceedings of the National Academy of Sciences of the United States of America, vol. 107, no. 7, pp. 2884-2889, 2010.

[89] T. Chae, Y. T. Kwon, R. Bronson, P. Dikkes, L. En, and L. Tsai, "Mice lacking p35, a neuronal specific activator of Cdk5, display cortical lamination defects, seizures, and adult lethality," Neuron, vol. 18, no. 1, pp. 29-42, 1997.

[90] T. Ohshima, J. M. Ward, C. Huh et al., "Targeted disruption of the cyclin-dependent kinase 5 gene results in abnormal corticogenesis, neuronal pathology and perinatal death," Proceedings of the National Academy of Sciences of the United States of America, vol. 93, no. 20, pp. 11173-11178, 1996.

[91] Z. H. Cheung and N. Y. Ip, "Cdk5: a multifaceted kinase in neurodegenerative diseases," Trends in Cell Biology, vol. 22, no. 3, pp. 169-175, 2012.

[92] Y. Wen, E. Planel, M. Herman et al., "Interplay between cyclindependent kinase 5 and glycogen synthase kinase $3 \beta$ mediated by neuregulin signaling leads to differential effects on tau phosphorylation and amyloid precursor protein processing," Journal of Neuroscience, vol. 28, no. 10, pp. 2624-2632, 2008.

[93] J. J. Hill, D. A. Callaghan, W. Ding, J. F. Kelly, and B. R. Chakravarthy, "Identification of okadaic acid-induced phosphorylation events by a mass spectrometry approach," Biochemical and Biophysical Research Communications, vol. 342, no. 3, pp. 791-799, 2006.

[94] S. P. Braithwaite, J. B. Stock, P. J. Lombroso, and A. C. Nairn, "Protein phosphatases and Alzheimer's Disease," Progress in Molecular Biology and Translational Science, vol. 106, pp. 343379, 2012.

[95] L. Martin, X. Latypova, C. M. Wilson, A. Magnaudeix, M. L. Perrin, and F. Terro, "Tau protein phosphatases in Alzheimer's disease: the leading role of PP2A," Ageing Research Reviews, vol. 12, no. 1, pp. 39-49, 2013.

[96] F. Liu, I. Grundke-Iqbal, K. Iqbal, and C. Gong, "Contributions of protein phosphatases PP1, PP2A, PP2B and PP5 to the regulation of tau phosphorylation," European Journal of Neuroscience, vol. 22, no. 8, pp. 1942-1950, 2005.

[97] Y. Xu, Y. Chen, P. Zhang, P. D. Jeffrey, and Y. Shi, "Structure of a protein phosphatase 2A holoenzyme: insights into B55mediated tau dephosphorylation," Molecular Cell, vol. 31, no. 6, pp. 873-885, 2008.

[98] S. Kins, A. Crameri, D. R. H. Evans, B. A. Hemmings, R. M. Nitsch, and J. Götz, "Reduced protein phosphatase 2A activity induces hyperphosphorylation and altered compartmentalization of tau in transgenic mice," Journal of Biological Chemistry, vol. 276, no. 41, pp. 38193-38200, 2001.

[99] H. Tanimukai, I. Grundke-Iqbal, and K. Iqbal, "Up-regulation of inhibitors of protein phosphatase-2A in Alzheimer's disease," American Journal of Pathology, vol. 166, no. 6, pp. 1761-1771, 2005.

[100] E. Sontag, A. Luangpirom, C. Hladik et al., "Altered expression levels of the protein phosphatase $2 \mathrm{~A} \mathrm{AB} \alpha \mathrm{C}$ enzyme are associated with Alzheimer disease pathology," Journal of Neuropathology and Experimental Neurology, vol. 63, no. 4, pp. 287-301, 2004.

[101] C. X. Gong, T. Lidsky, J. Wegiel, L. Zuck, I. Grundke-Iqbal, and K. Iqbal, "Phosphorylation of microtubule-associated protein tau is regulated by protein phosphatase $2 \mathrm{~A}$ in mammalian brain. Implications for neurofibrillary degeneration in Alzheimer's disease," Journal of Biological Chemistry, vol. 275, no. 8, pp. 5535-5544, 2000.

[102] K. Ando, K. Iijima, J. I. Elliott, Y. Kirino, and T. Suzuki, "Phosphorylation-dependent regulation of the interaction of amyloid precursor protein with Fe65 affects the production of $\beta$-amyloid," Journal of Biological Chemistry, vol. 276, no. 43, pp. 40353-40361, 2001.

[103] K. Iijima, K. Ando, S. Takeda et al., "Neuron-specific phosphorylation of Alzheimer's $\beta$-amyloid precursor protein by cyclindependent kinase 5," Journal of Neurochemistry, vol. 75, no. 3, pp. 1085-1091, 2000.

[104] R. Liu, X.-W. Zhou, H. Tanila et al., "Phosphorylated PP2A (tyrosine 307) is associated with Alzheimer neurofibrillary pathology: in focus," Journal of Cellular and Molecular Medicine, vol. 12, no. 1, pp. 241-257, 2008.

[105] E. Sontag, V. Nunbhakdi-Craig, J. Sontag et al., "Protein phosphatase 2A methyltransferase links homocysteine metabolism with tau and amyloid precursor protein regulation," Journal of Neuroscience, vol. 27, no. 11, pp. 2751-2759, 2007.

[106] E. E. F. Da Cruz Silva, E. O. A. Da Cruz Silva, C. T. Zaia, and P. Greengard, "Inhibition of protein phosphatase 1 stimulates secretion of Alzheimer amyloid precursor protein," Molecular Medicine, vol. 1, no. 5, pp. 535-541, 1995.

[107] M. Holzer, M. K. Brückner, M. Beck, V. Bigl, and T. Arendt, "Modulation of APP processing and secretion by okadaic acid in primary guinea pig neurons," Journal of Neural Transmission, vol. 107, no. 4, pp. 451-461, 2000.

[108] I. De Baere, R. Derua, V. Janssens et al., "Purification of porcine brain protein phosphatase 2A leucine carboxyl methyltransferase and cloning of the human homologue," Biochemistry, vol. 38, no. 50, pp. 16539-16547, 1999.

[109] J. M. Sontag, V. Nunbhakdi-Craig, L. Montgomery, E. Arning, T. Bottiglieri, and E. Sontag, "Folate deficiency induces in vitro and mouse brain region-specific downregulation of leucine carboxyl methyltransferase- 1 and protein phosphatase $2 \mathrm{~A} \mathrm{~B} \alpha$ subunit expression that correlate with enhanced tau phosphorylation," Journal of Neuroscience, vol. 28, no. 45, pp. 11477-11487, 2008

[110] V. Vogelsberg-Ragaglia, T. Schuck, J. Q. Trojanowski, and V. M.-Y. Lee, "PP2A mRNA expression is quantitatively decreased in Alzheimer's disease hippocampus," Experimental Neurology, vol. 168, no. 2, pp. 402-412, 2001.

[111] L. H. Wang and S. M. Strittmatter, "Brain CRMP forms heterotetramers similar to liver dihydropyrimidinase," Journal of Neurochemistry, vol. 69, no. 6, pp. 2261-2269, 1997.

[112] N. Hamajima, K. Matsuda, S. Sakata, N. Tamaki, M. Sasaki, and M. Nonaka, "A novel gene family defined by human dihydropyrimidinase and three related proteins with differential tissue distribution," Gene, vol. 180, no. 1-2, pp. 157-163, 1996.

[113] L. H. Wang and S. M. Strittmatter, "A family of rat CRMP genes is differentially expressed in the nervous system," Journal of Neuroscience, vol. 16, no. 19, pp. 6197-6207, 1996.

[114] N. Inagaki, K. Chihara, N. Arimura et al., "CRMP-2 induces axons in cultured hippocampal neurons," Nature Neuroscience, vol. 4, no. 8, pp. 781-782, 2001. 
[115] T. Morita and K. Sobuě, "Specification of neuronal polarity regulated by local translation of CRMP2 and tau via the mTORp70S6K pathway," Journal of Biological Chemistry, vol. 284, no. 40, pp. 27734-27745, 2009.

[116] N. Arimura, C. Menager, Y. Fukata, and K. Kaibuchi, "Role of CRMP-2 in neuronal polarity," Journal of Neurobiology, vol. 58, no. 1, pp. 34-47, 2004.

[117] N. Arimura, C. Ménager, Y. Kawano et al., "Phosphorylation by Rho kinase regulates CRMP-2 activity in growth cones," Molecular and Cellular Biology, vol. 25, no. 22, pp. 9973-9984, 2005.

[118] T. Yoshimura, Y. Kawano, N. Arimura, S. Kawabata, A. Kikuchi, and K. Kaibuchi, "GSK- $3 \beta$ regulates phosphorylation of CRMP2 and neuronal polarity," Cell, vol. 120, no. 1, pp. 137-149, 2005.

[119] M. P. M. Soutar, P. Thornhill, A. R. Cole, and C. Sutherland, "Increased CRMP2 phosphorylation is observed in Alzheimer's disease; does this tell us anything about disease development?" Current Alzheimer Research, vol. 6, no. 3, pp. 269-278, 2009.

[120] H. Asai, S. Ikezu, M. Varnum, and T. Ikezu, "Phosphorylation of collapsin response mediator protein-2 and axonal degeneration in transgenic mice expressing a familial Alzheimer's disease mutant of APP and tau-tubulin kinase 1," Alzheimer's \& Dementia, vol. 8, no. 4, pp. 649-650, 2012.

[121] A. Yoneda, M. Morgan-Fisher, R. Wait, J. R. Couchman, and U. M. Wewer, "A collapsin response mediator protein 2 isoform controls myosin II-mediated cell migration and matrix assembly by trapping ROCK II," Molecular and Cellular Biology, vol. 32, no. 10, pp. 1788-1804, 2012.

[122] T. Kimura, N. Arimura, Y. Fukata, H. Watanabe, A. Iwamatsu, and K. Kaibuchi, "Tubulin and CRMP-2 complex is transported via Kinesin-1," Journal of Neurochemistry, vol. 93, no. 6, pp. 13711382, 2005.

[123] Y. Kawano, T. Yoshimura, D. Tsuboi et al., "CRMP-2 is involved in kinesin-1-dependent transport of the Sra-1/WAVE1 complex and axon formation," Molecular and Cellular Biology, vol. 25, no. 22, pp. 9920-9935, 2005.

[124] T. Nishimura, Y. Fukata, K. Kato et al., "CRMP-2 regulates polarized Numb-mediated endocytosis for axon growth," Nature Cell Biology, vol. 5, no. 9, pp. 819-826, 2003.

[125] M. Tan, S. Ma, Q. Huang, K. Hu, B. Song, and M. Li, "GSK$3 \alpha / \beta$-mediated phosphorylation of CRMP-2 regulates activitydependent dendritic growth," Journal of Neurochemistry, vol. 125, no. 5, pp. 685-697, 2013.

[126] Y. Fukata, T. J. Itoh, T. Kimura et al., "CRMP-2 binds to tubulin heterodimers to promote microtubule assembly," Nature Cell Biology, vol. 4, no. 8, pp. 583-591, 2002.

[127] G. F. Reis, G. Yang, L. Szpankowski et al., "Molecular motor function in axonal transport in vivo probed by genetic and computational analysis in Drosophila," Molecular Biology of the Cell, vol. 23, no. 9, pp. 1700-1714, 2012.

[128] T. L. Falzone and G. B. Stokin, "Imaging amyloid precursor protein in vivo: an axonal transport assay," Methods in Molecular Biology, vol. 846, pp. 295-303, 2012.

[129] K. Iqbal and I. Grundke-Iqbal, "Alzheimer abnormally phosphorylated tau is more hyperphosphorylated than the fetal tau and causes the disruption of microtubules," Neurobiology of Aging, vol. 16, no. 3, pp. 375-379, 1995.

[130] H. Potter, S. Borysov, C. Ari et al., "A $\beta$ inhibits specific kinesin motors involved in both mitosis and neuronal function; potential implications for neurogenesis and neuroplasticity in Alzheimer's disease and Down syndrome," Alzheimer's \& Dementia, vol. 7, no. 4, p. 24, 2011.
[131] K. R. Brunden, Y. Yao, J. S. Potuzak et al., "The characterization of microtubule-stabilizing drugs as possible therapeutic agents for Alzheimer's disease and related tauopathies," Pharmacological Research, vol. 63, no. 4, pp. 341-351, 2011.

[132] X. Ye, W. Tai, and D. Zhang, “The early events of Alzheimer's disease pathology: from mitochondrial dysfunction to BDNF axonal transport deficits," Neurobiology of Aging, vol. 33, no. 6, pp. 1122.e1-1122.e10, 2012.

[133] P. Mao and P. H. Reddy, "Aging and amyloid beta-induced oxidative DNA damage and mitochondrial dysfunction in Alzheimer's disease: implications for early intervention and therapeutics," Biochimica et Biophysica Acta, vol. 1812, no. 11, pp. 1359-1370, 2011.

[134] L. S. B. Goldstein, “Axonal transport and Alzheimer's diseasein," in Encyclopedia of Neuroscience, R. S. Larry, Ed., pp. 1189-1194, Academic Press, Oxford, UK, 2009.

[135] F. Mitsuyama, Y. Futatsugi, M. Okuya et al., "Stimulationdependent intraspinal microtubules and synaptic failure in Alzheimer's disease: a review," International Journal of Alzheimer's Disease, vol. 2012, Article ID 519682, 7 pages, 2012.

[136] M. Paula-Barbosa, M. A. Tavares, and A. Cadete-Leite, "A quantitative study of frontal cortex dendritic microtubules in patients with Alzheimer's disease," Brain Research, vol. 417, no. 1, pp. 139-142, 1987.

[137] J. C. Fiala, "Mechanisms of amyloid plaque pathogenesis," Acta Neuropathologica, vol. 114, no. 6, pp. 551-571, 2007.

[138] R. Adalbert, A. Nogradi, E. Babetto et al., "Severely dystrophic axons at amyloid plaques remain continuous and connected to viable cell bodies," Brain, vol. 132, no. 2, pp. 402-416, 2009.

[139] L. S. B. Goldstein, "Kinesin molecular motors: transport pathways, receptors, and human disease," Proceedings of the National Academy of Sciences of the United States of America, vol. 98, no. 13, pp. 6999-7003, 2001.

[140] C. Dhaenens, E. Van Brussel, S. Schraen-Maschke, F. Pasquier, A. Delacourte, and B. Sablonnire, "Association study of three polymorphisms of kinesin light-chain 1 gene with Alzheimer's disease," Neuroscience Letters, vol. 368, no. 3, pp. 290-292, 2004.

[141] L. Szpankowski, S. E. Encalada, and L. S. B. Goldstein, "Subpixel colocalization reveals amyloid precursor protein-dependent kinesin- 1 and dynein association with axonal vesicles," Proceedings of the National Academy of Sciences of the United States of America, vol. 109, no. 22, pp. 8582-8587, 2012.

[142] G. B. Stokin, C. Lillo, T. L. Falzone et al., "Axonopathy and transport deficits early in the pathogenesis of Alzheimer's diseases," Science, vol. 307, no. 5713, pp. 1282-1288, 2005.

[143] A. Kamal, G. B. Stokin, Z. Yang, C. Xia, and L. S. B. Goldstein, "Axonal transport of amyloid precursor protein is mediated by direct binding to the kinesin light chain subunit of kinesin-I," Neuron, vol. 28, no. 2, pp. 449-459, 2000.

[144] G. Traina, G. Federighi, and M. Brunelli, "Up-regulation of kinesin light-chain 1 gene expression by acetyl-l-carnitine: therapeutic possibility in Alzheimer's disease," Neurochemistry International, vol. 53, no. 6-8, pp. 244-247, 2008.

[145] T. L. Falzone, S. Gunawardena, D. McCleary, G. F. Reis, and L. S. B. Goldstein, "Kinesin-1 transport reductions enhance human tau hyperphosphorylation, aggregation and neurodegeneration in animal models of tauopathies," Human Molecular Genetics, vol. 19, no. 22, Article ID ddq363, pp. 4399-4408, 2010. 
[146] T. T. Quach, A. Duchemin, V. Rogemond et al., "Involvement of collapsin response mediator proteins in the neurite extension induced by neurotrophins in dorsal root ganglion neurons," Molecular and Cellular Neuroscience, vol. 25, no. 3, pp. 433-443, 2004. 


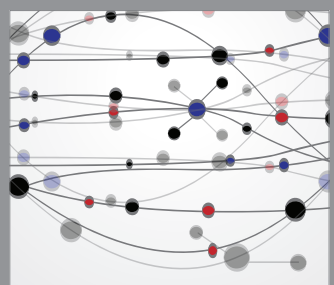

The Scientific World Journal
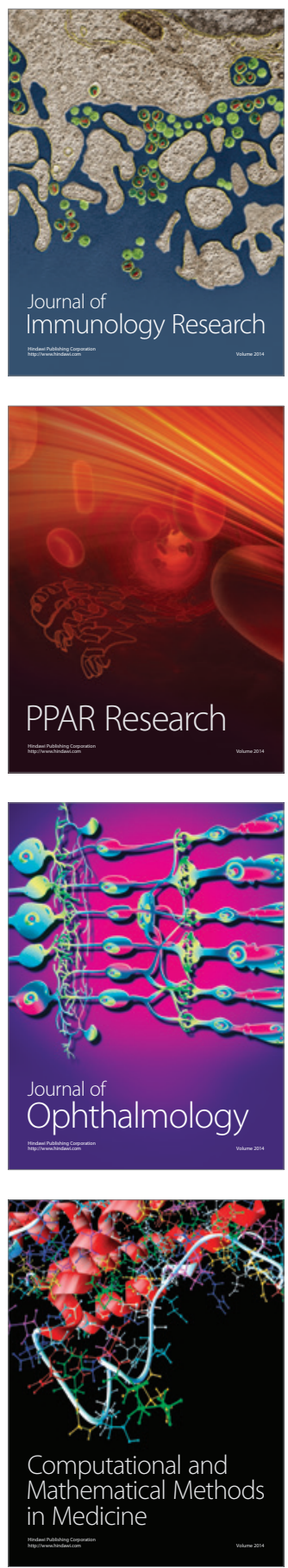

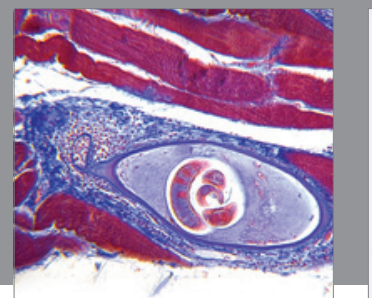

Gastroenterology

Research and Practice
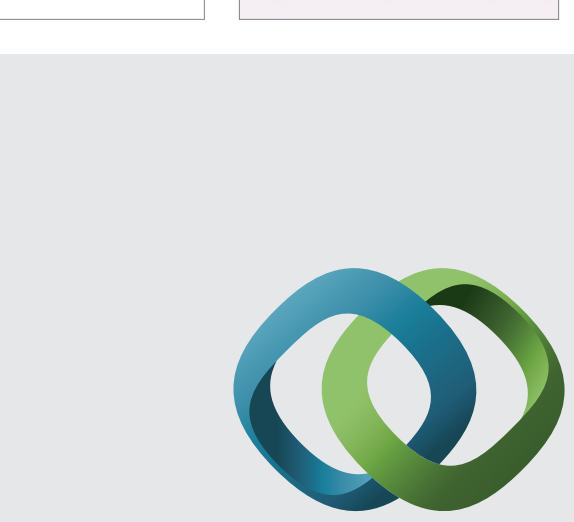

\section{Hindawi}

Submit your manuscripts at

http://www.hindawi.com
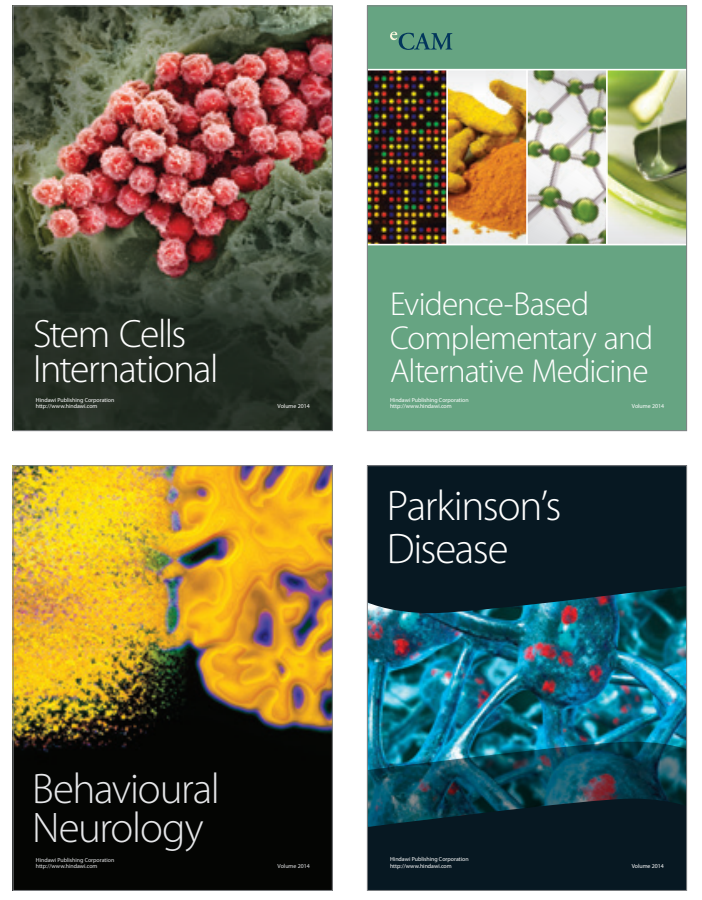
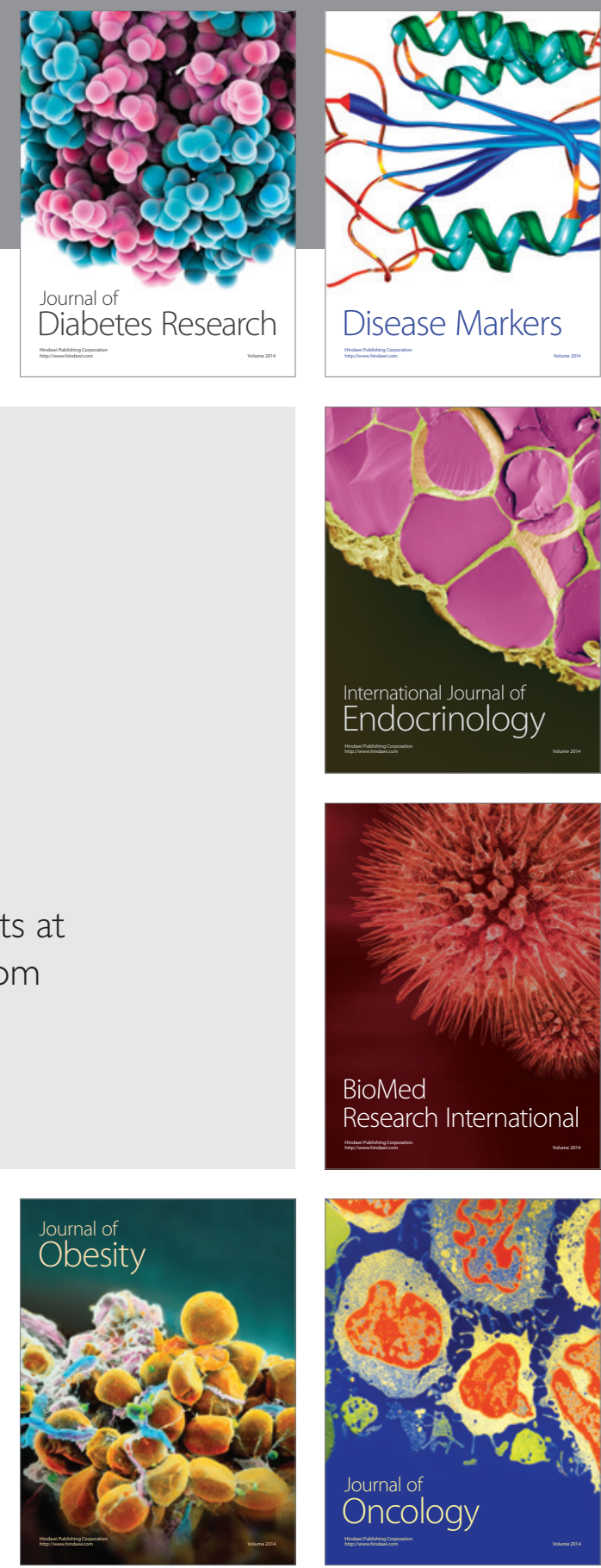

Disease Markers
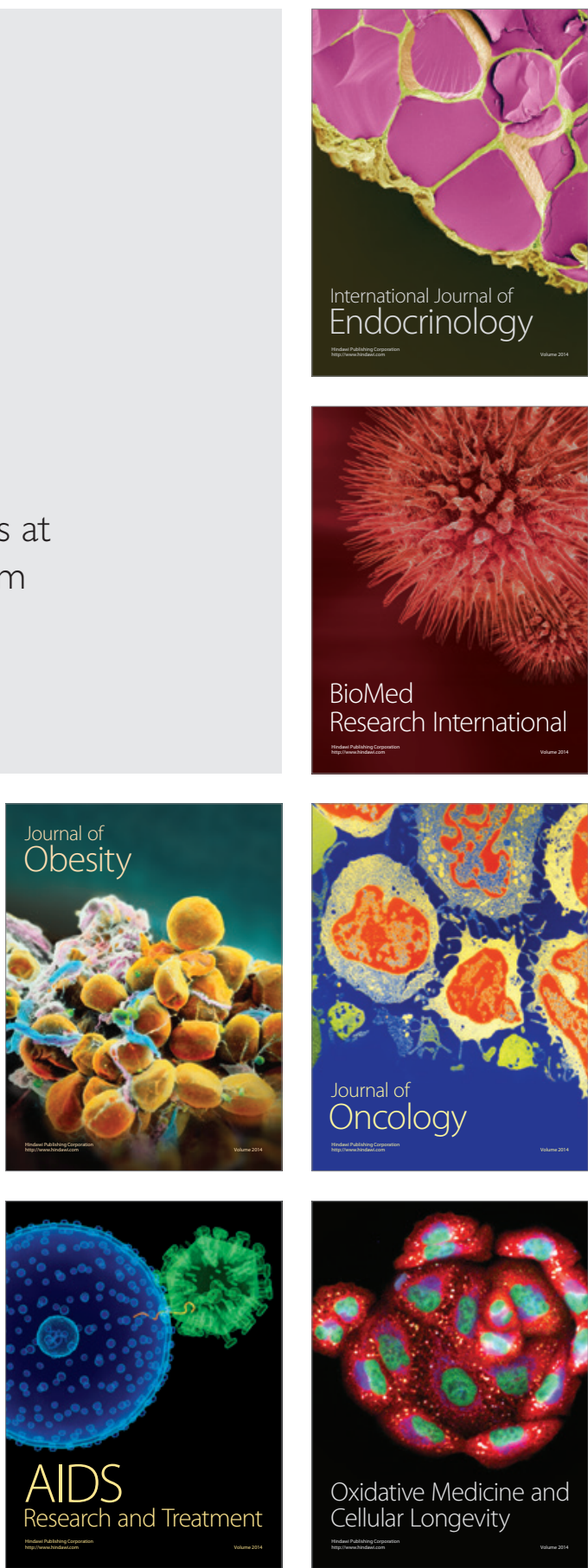